\title{
Diverting Radical-Anionic C-H Amidation to a C-N/C-O Cascade for the Construction of Hydroxyisoindolines from Unprotected Amides
}

\author{
Quintin Elliott, $\stackrel{ \pm}{ }$ Gabriel dos Passos Gomes, ${ }^{\star}$ Christopher J. Evoniuk, and Igor V. Alabugin ${ }^{* \pm}$ \\ ${ }^{ \pm}$current address: Department of Chemistry and Biochemistry, Florida State University, \\ Tallahassee, Florida 32306, United States \\ * current address: Department of Chemistry and Department of Computer Science, University of \\ Toronto, Toronto, Ontario, Canada
}

\begin{abstract}
:
An intramolecular $\mathrm{C}\left(\mathrm{sp}^{3}\right)-\mathrm{H}$ amidation proceeds in the presence of $t$-BuOK, molecular oxygen, and DMF. The success of this reaction hinges on the deprotonation of a mildly acidic N-H bond and selective radical activation of a benzylic $\mathrm{C}\left(\mathrm{sp}^{3}\right)-\mathrm{H}$ bond towards hydrogen atom transfer (HAT). DFT calculations suggest a thermodynamically favorable sequence of steps mediated by the generation of a radical-anion intermediate. As this intermediate starts to form a twocentered/three-electron $(2 c, 3 e) \mathrm{C}$-N bond, the extra electron is "ejected" into the $\pi^{*}$-orbital of the aromatic core. The resulting cyclic radical-anion is readily oxidized by molecular oxygen to forge the $\mathrm{C}-\mathrm{N}$ bond of the product. The transformation of a relatively weak reductant into a stronger reductant (i.e., "reductant upconversion") allows one to use mild oxidants such as molecular oxygen. In contrast, the second stage of $\mathrm{NH} / \mathrm{CH}$ activation forms a highly stabilized radical-anion intermediate incapable of electron transfer to molecular oxygen. Hence, the oxidation is impossible and an alternative reaction path opens via coupling between the radical anion intermediate and either superoxide or hydroperoxide radical. The hydroperoxide intermediate transforms into the final hydroxyisoindoline products under basic conditions. The use of TEMPO as an additive was found to activate less reactive amides. The combination of experimental and computational data outlines a conceptually new mechanism for the conversion of unprotected amides into hydroxyisoindolines proceeding as a sequence of $\mathrm{C}-\mathrm{H}$ amidation and $\mathrm{C}-\mathrm{H}$ oxidation.
\end{abstract}

\section{Introduction}

Due to their abundance, the $\mathrm{C}\left(\mathrm{sp}^{3}\right)-\mathrm{H}$ bonds offer an excellent starting point for the functionalization of organic compounds. ${ }^{1}$ However, the productive use of $\mathrm{C}-\mathrm{H}$ bonds is complicated due to the difficulties associated with their selective activation. ${ }^{2}$ These challenges prompt chemists to search for the new approaches for utilizing the $\mathrm{C}-\mathrm{H}$ bonds as a reactive organic functionality. ${ }^{3}$

$\mathrm{C}-\mathrm{H}$ amination couples $\mathrm{C}-\mathrm{H}$ activation with the concomitant formation of a $\mathrm{C}-\mathrm{N}$ bond and opens new avenues to the synthesis of nitrogen-containing organic compounds. ${ }^{4}$ This approach has evolved into a versatile group of reactions that overcome the challenges faced with $\mathrm{C}-\mathrm{H}$ activation and $\mathrm{C}-\mathrm{N}$ bond formation. We suggest that, depending upon nitrogen's participation in $\mathrm{C}-\mathrm{H}$ activation and $\mathrm{C}-\mathrm{N}$ bond formation, one can broadly classify $\mathrm{C}-\mathrm{H}$ amination reactions within the following four approaches: a) $\mathrm{C}-\mathrm{H}$ activation directly coupled with $\mathrm{C}-\mathrm{N}$ formation (direct activation), b) $\mathrm{C}-\mathrm{H}$ activation with delayed $\mathrm{C}-\mathrm{N}$ bond formation, c) $\mathrm{N}$-assisted $\mathrm{C}-\mathrm{H}$ activation, and d) independent $\mathrm{C}-\mathrm{H} / \mathrm{N}-\mathrm{H}$ activation (Scheme 1). 


\section{a) Direct Activation}

- Nitrogen is responsible for $\mathrm{C}-\mathrm{H}$ activation

- Nitrogen is responsible for $\mathrm{C}-\mathrm{N}$ and $\mathrm{N}-\mathrm{H}$ bond formation

Singlet Nitrene

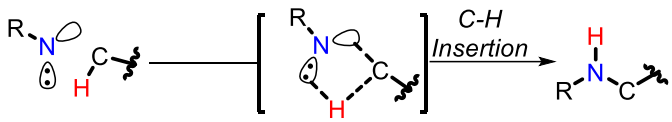

$\underline{\text { Triplet Nitrene }}$

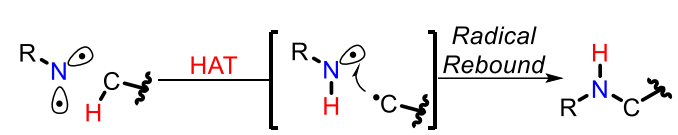

\section{b) C-H Activation with Delayed C-N Bond Formation}

- Nitrogen is responsible for $\mathrm{C}-\mathrm{H}$ activation

- Additional reagent needed for $\mathrm{C}-\mathrm{N}$ bond formation

- Usually, remote intramolecular activation

Nitrogen Centered Radical

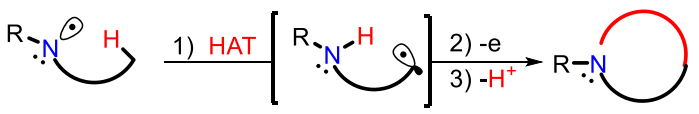

Conjugated Nitrogen Centered Radical Cation

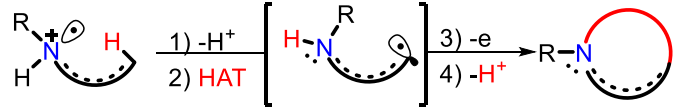

c) Nitrogen-Assisted C-H Activation

- Nitrogen is not directly involved in C-H activation

- Nitrogen may play a secondary role as directing group

Transition Metal C-H activation

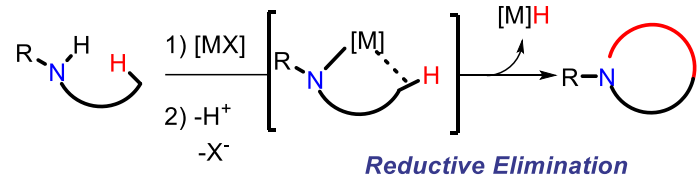

\section{d) Independent N-H/C-H Activation}

- Two independently formed reactive intermediates: $\mathrm{N}$ - and C-centered

Dianion "Reductive Elimination without a metal"
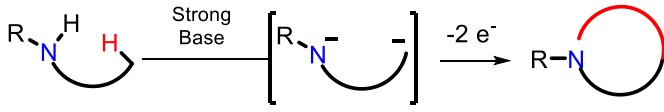

Radical-anion

This work
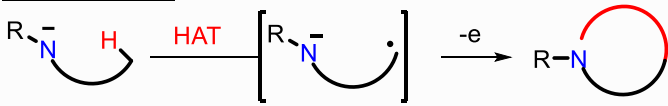

Scheme 1. Selected examples for the four approaches to C-N bond formation via C-H activation. All carbons are tetravalent, the non-participating $\mathrm{C}-\mathrm{H}$ bonds omitted for clarity.

In direct activation (Scheme 1a), nitrogen is responsible for the activation of $\mathrm{C}-\mathrm{H}$ bonds and the formation of both the C-N and the N-H bonds. This mode of activation can be achieved if $\mathrm{N}$ has two non-bonding orbitals, populated by the total of two electrons. It is observed with highly coordinatively unsaturated species, such as as nitrenes and nitrenium ions where nitrogen can insert directly into a $\mathrm{C}-\mathrm{H}$ bond. This process is analogous to carbene insertion into $\mathrm{C}-\mathrm{H}$ bonds and can proceed in either a stepwise or concerted manner. ${ }^{5}$

In $\mathrm{C}-\mathrm{H}$ activation with delayed $\mathrm{C}-\mathrm{N}$ bond formation (Scheme $1 \mathrm{~b}$ ), nitrogen assists in $\mathrm{C}-\mathrm{H}$ activation by breaking the $\mathrm{C}-\mathrm{H}$ bond but the $\mathrm{C}-\mathrm{N}$ bond forming step needs an additional participant (e.g., an external oxidant). This process also requires an electron-deficient nitrogen-centered intermediate, i.e., a radical ${ }^{6}$ or a radical-cation. ${ }^{7}$ If placed in the proximity to a $\mathrm{C}-\mathrm{H}$ bond, a nitrogen centered radical can (usually intramolecularly) abstract a hydrogen atom, forming a carbon centered radical. A C-N bond is formed by trapping this radical, but usually only after a subsequent step that "prepares" the participating atoms for this event (i.e., oxidation of carbon and/or deprotonation of nitrogen).

Alternatively, activation of a $\mathrm{C}-\mathrm{H}$ bond can be achieved by deprotonation of a nitrogen radical-cation, prepared by oxidation of an amine. Such deprotonation usually proceeds at the $\alpha$ position where it can provide a stabilized C-centered $\alpha$-radical. ${ }^{8}$ Such radicals can be trapped in a variety of ways, many of which do not lead to the $\mathrm{C}-\mathrm{N}$ bond formation. However, in conjugated radical-cations, activation of a remote $\mathrm{C}-\mathrm{H}$ bond becomes possible. For example, we have shown 
that it can be utilized to form $\mathrm{C}-\mathrm{N}$ bonds between the activating $\mathrm{NH}_{2}$ moiety and the activated $\mathrm{CH}_{2}$ group five bonds away. ${ }^{9,10}$

In the $\mathrm{N}$-assisted $\mathrm{C}-\mathrm{H}$ activation reactions (Scheme 1c), nitrogen does not directly participate in the $\mathrm{C}-\mathrm{H}$ activation step but can trap the $\mathrm{C}$-centered reactive species once they are formed. An external reagent, such as an appropriately chosen transition metal, may be used for C$\mathrm{H}$ activation. An appealing strategy is to use nitrogen as a directing group, binding to the transition metal and guiding it to the targeted $\mathrm{C}-\mathrm{H}$ bond. ${ }^{11}$ The close interactions of the transition metal center with nitrogen allow for a $\mathrm{C}-\mathrm{N}$ bond forming step to proceed after the $\mathrm{C}-\mathrm{H}$ activation event. ${ }^{12}$ In particular, a new $\mathrm{C}-\mathrm{N}$ bond can be formed via reductive elimination at the transition metal. ${ }^{13}$

The fourth, conceptually different approach is to activate both the N-H and the C-H bonds by independently converting them into reactive intermediates (Scheme 1d). By decoupling the two steps, this approach potentially becomes the most flexible but the conditions for selective and independent $\mathrm{N}-\mathrm{H} / \mathrm{C}-\mathrm{H}$ activation are not always easy to achieve. The possible situations here involve i) formation of $\mathrm{N}$ - and $\mathrm{C}$ - centered radicals, ii) formation of a radical and an anion (usually, $\mathrm{C}$-radical and $\mathrm{N}$-anion), and iii) formation of an $\mathrm{N}$-anion and a $\mathrm{C}$-anion. The latter two paths have to be terminated by $1 \mathrm{e}$ and $2 \mathrm{e}$ oxidations, respectively, to yield the "normal" two-centered/twoelectron $(2 c, 2 e) \mathrm{C}-\mathrm{N}$ bond.

Productive combination of two reactive intermediates is efficient only when one of these intermediates is relatively persistent. ${ }^{14}$ From that perspective, formation of stable $\mathrm{N}$-anions (approaches ii and iii) is attractive (Scheme 1d).

Sarpong and coworkers illustrated that a C,N dianion, formed in the presence of strong bases can form a C-N bond upon a two-electron oxidation with $\mathrm{I}_{2}$ (iii). ${ }^{15}$ This approach, which can be conceptually considered "reductive elimination without a metal" allows C-N bond formation without the need for preoxidized coupling partners via the formal loss of $\mathrm{H}_{2}$. Formation of five-, six-, and seven-membered rings was found to proceed even in conformationally unbiased substrates.

In our work, we are exploring the advantage of a three-electron approach (ii). ${ }^{10}$ Because the three electron radical/anion interactions are potentially stabilizing, they can lead to favorable $\mathrm{C} / \mathrm{N}$ precoordination that can lead to instantaneous $\mathrm{C}-\mathrm{N}$ bond formation upon oxidation. In contrast, the $4 \mathrm{e}$ anion/anion interactions are always repulsive and, hence, the $\mathrm{C}, \mathrm{N}$-dianion may adopt a conformation that is not conducive to the bond formation.

We have recently illustrated the value of the radical-anionic approach in an intramolecular $\mathrm{C}\left(\mathrm{sp}^{3}\right)-\mathrm{H}$ aminations with unprotected anilines using $t$-BuOK, molecular oxygen, and $\mathrm{N}, \mathrm{N}-$ dimethylformamide (DMF). ${ }^{10}$ This method relies on a sequence of $\mathrm{N}-\mathrm{H}$ deprotonations and selective $\mathrm{H}$-atom transfers (HAT) from weakened $\mathrm{C}(\mathrm{sp} 3)-\mathrm{H}$ bonds for generating a radical-anion intermediate (Scheme 3a). This intermediate forms a thermodynamically favored two-center/threeelectron $(2 c, 3 e)$ "half bond", where one of the electrons is forced to occupy a high energy antibonding orbital ("electron upconversion", Scheme 2). ${ }^{16}$ The newly formed radical-anion can then be readily oxidized into a "normal" $2 c, 2 e$ bond by a mild oxidant, such as molecular oxygen. By generating a radical anion in situ we effectively take a weak reductant and evolve it into a more potent reductant. Such "electron upconversion" 16 allows for an effective use of such a mild oxidant as molecular oxygen. By avoiding stronger oxidants, we prevented undesired product oxidation in our cascade reactions that yield expanded N-doped polyaromatic systems. 


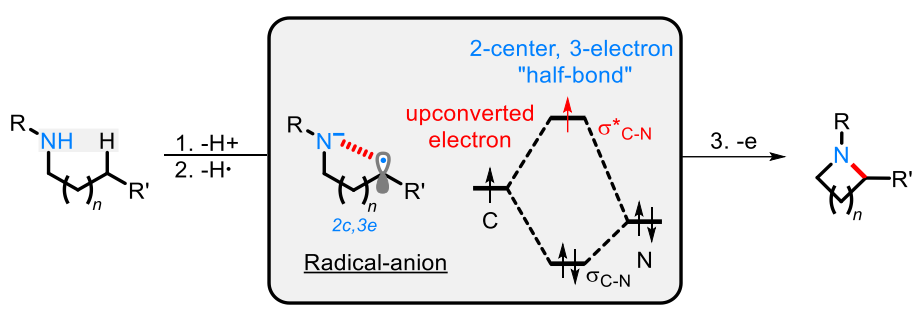

Scheme 2. Three steps in the proposed $\mathrm{C}-\mathrm{H} / \mathrm{N}-\mathrm{H}$ activation and the mechanism of electron upconversion.

In this manuscript, we expand this approach for the construction of cyclic products using amides, a less nucleophilic nitrogen source (Scheme 3b). We will show how this structural modification of the reactants diverts the cascade towards incorporation of a $\mathrm{C}-\mathrm{O}$ bond forming step, ${ }^{17}$ so it can open a new synthetic route to 3-hydroxyisoindolinones.

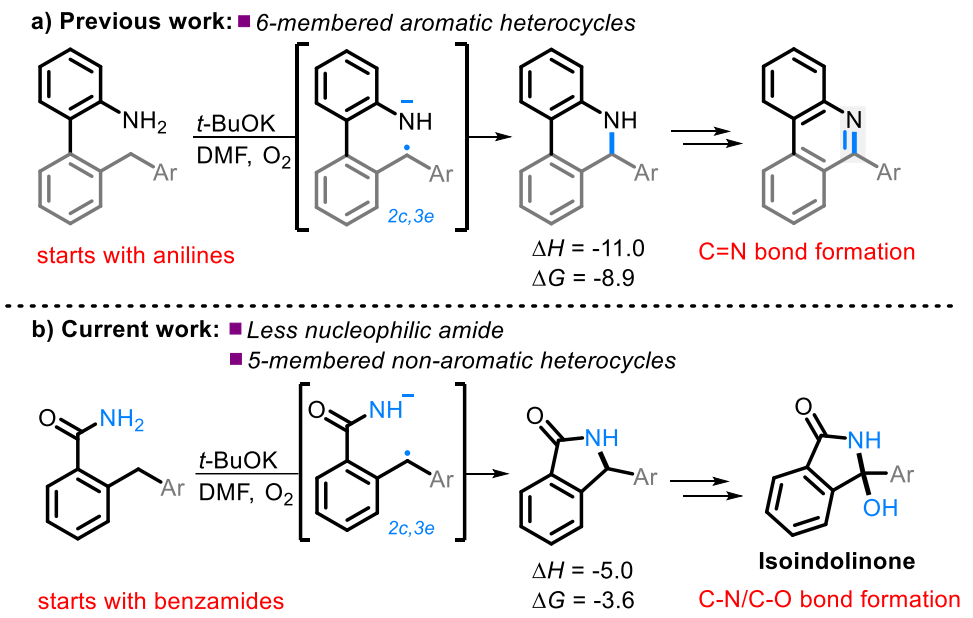

Scheme 3. Expanding previous work to utilize less nucleophilic amides, as well as the formation of non-aromatic five membered heterocycles, and C-N/C-O bond formation. All energies are in $\mathrm{kcal} / \mathrm{mol}$.

This isoindolinone scaffold has been shown to produce antitumor effects by inhibiting MDM2-p53 interactions, ${ }^{18}$ as well as serving as the antihypertensive agent Chlortalidone. ${ }^{19}$ This heterocyclic core can be found in several natural compounds. ${ }^{20}$ Furthermore, a variety of postsynthetic modifications of the core hydroxyisoindoline structure are possible (Scheme 4) including enantioselective transformations mediated by chiral phosphoric acids. ${ }^{21^{22} 2}$ Transition metal catalysis was also utilized for making chiral isoindolinones and spiroisoindolinones. ${ }^{23}$ 


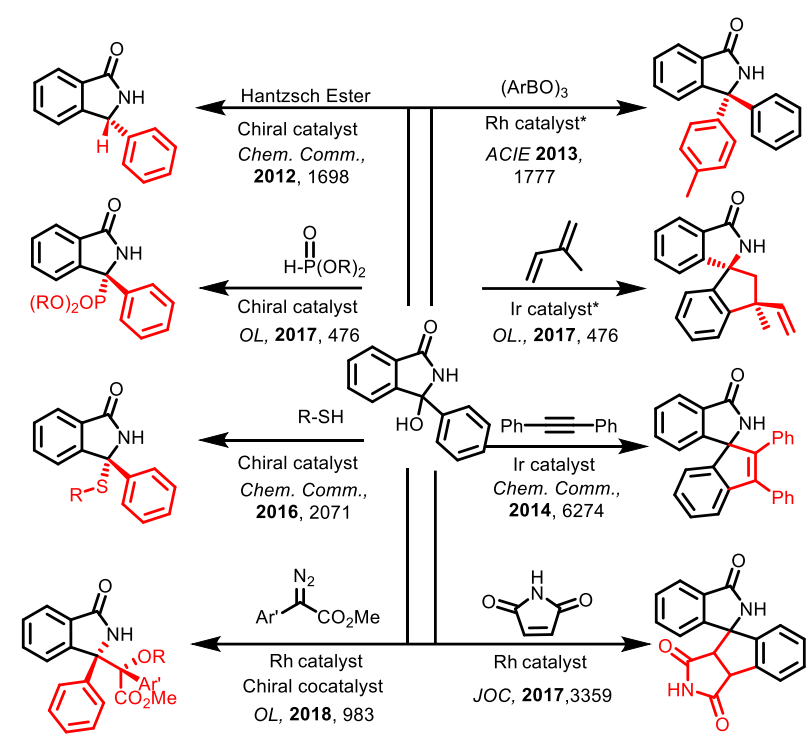

Scheme 4. Post-synthetic modifications for 3-hydroxyisoindolinone.

The successful use of amides as nucleophilic partners in a base-promoted oxidative $\mathrm{C}\left(\mathrm{sp}^{3}\right)$ $\mathrm{H}$ amidation yields isoindolinones under transition-metal free conditions. Because the presence of transition-metal impurities should be minimized in manufacturing medicinal compounds ${ }^{24}$ our transition-metal-free alternative can be an attractive choice for the synthesis of isoindolinonebased medicinal products.

\section{Results and discussion}

We began by subjecting amide $1 \mathrm{a}(0.01 \mathrm{mmol})$ to the previously optimized conditions, (i.e., DMF, $4 \AA$-molecular sieves (MS), $\mathrm{O}_{2}$ atmosphere and 3 equivalents of t-BuOK at room temperature) for 4 hours. ${ }^{9}$ To our delight, $2 \mathbf{a}$ was formed in an excellent yield, $87 \%$ (Table 1, entry 1). When DMSO and THF were used in place of DMF, the yields of $\mathbf{2 a}$ were lower (36\% and $47 \%$, entries 2 and 5). Furthermore, when DMF was replaced with acetonitrile, toluene, or DCM, 2a was not observed (entry 3-4, 6). These results prompted us to perform the rest of our studies in DMF.

We then tested five additional bases (entry 7-11). The tert-butoxide salts produced $\mathbf{2 a}$ in the highest yields. Interestingly, the size of the counterion impacts the conversion of 1a into $\mathbf{2 a}$. While the difference was small for the sodium and potassium tert-butoxide salts $(87 \%$ vs $79 \%$ respectively), a noticeable difference in yield was observed between the $\mathrm{K}, \mathrm{Na}$, and Li hydroxides $(55 \%, 31 \%,<1 \%$ respectively). Fewer than 3 equivalents of base (entry 12-13) were insufficient for the full consumption of the starting material. More than 3 equivalents of base (entry 14-15) were found to be unnecessary as there was no improvement in yield.

We then varied the reaction time (entry 16-18) and observed full consumption of starting material within one hour. Finally, when the reaction vial was charged with air instead of oxygen, 2a was produced in $75 \%$ yield (entry 19). However, the rate of the reaction was slower and not all of $1 \mathbf{a}$ was consumed.

\section{Table 1. Optimization Table}




\begin{tabular}{|c|c|c|c|c|c|c|}
\hline Entry & Solvent & Base & $\mathrm{Eq}$ & Atm & Time & Yield \% \\
\hline 1 & $\mathrm{DMF}$ & $t$-BuOK & 3 & $\mathrm{O}_{2}$ & $4 \mathrm{~h}$ & $87 \%$ \\
\hline 2 & DMSO & $t$-BuOK & 3 & $\mathrm{O}_{2}$ & $4 \mathrm{~h}$ & $36 \%$ \\
\hline 3 & $\mathrm{MeCN}$ & $t-\mathrm{BuOK}$ & 3 & $\mathrm{O}_{2}$ & $4 \mathrm{~h}$ & $<1 \%$ \\
\hline 4 & Toluene & $t-\mathrm{BuOK}$ & 3 & $\mathrm{O}_{2}$ & $4 \mathrm{~h}$ & $<1 \%$ \\
\hline 5 & $\mathrm{THF}$ & $t$-BuOK & 3 & $\mathrm{O}_{2}$ & $4 \mathrm{~h}$ & $47 \%$ \\
\hline 6 & DCM & $t$-BuOK & 3 & $\mathrm{O}_{2}$ & $4 \mathrm{~h}$ & $<1 \%$ \\
\hline 7 & DMF & $t$-BuONa & 3 & $\mathrm{O}_{2}$ & $4 \mathrm{~h}$ & $79 \%$ \\
\hline 8 & DMF & $\mathrm{KOH}$ & 3 & $\mathrm{O}_{2}$ & $4 \mathrm{~h}$ & $55 \%$ \\
\hline 9 & DMF & $\mathrm{NaOH}$ & 3 & $\mathrm{O}_{2}$ & $4 \mathrm{~h}$ & $31 \%$ \\
\hline 10 & DMF & $\mathrm{LiOH}$ & 3 & $\mathrm{O}_{2}$ & $4 \mathrm{~h}$ & $<1 \%$ \\
\hline 11 & DMF & $\mathrm{K}_{2} \mathrm{CO}_{3}$ & 3 & $\mathrm{O}_{2}$ & $4 \mathrm{~h}$ & $<1 \%$ \\
\hline 12 & DMF & $t-\mathrm{BuOK}$ & 1 & $\mathrm{O}_{2}$ & $4 \mathrm{~h}$ & $55 \%$ \\
\hline 13 & DMF & $t$-BuOK & 2 & $\mathrm{O}_{2}$ & $4 \mathrm{~h}$ & $68 \%$ \\
\hline 14 & DMF & $t$-BuOK & 4 & $\mathrm{O}_{2}$ & $4 \mathrm{~h}$ & $85 \%$ \\
\hline 15 & DMF & $t$-BuOK & 5 & $\mathrm{O}_{2}$ & $4 \mathrm{~h}$ & $88 \%$ \\
\hline 16 & DMF & $t$-BuOK & 3 & $\mathrm{O}_{2}$ & $3 \mathrm{~h}$ & $85 \%$ \\
\hline 17 & DMF & $t$-BuOK & 3 & $\mathrm{O}_{2}$ & $2 \mathrm{~h}$ & $82 \%$ \\
\hline 18 & DMF & $t-\mathrm{BuOK}$ & 3 & $\mathrm{O}_{2}$ & $1 \mathrm{~h}$ & $84 \%$ \\
\hline 19 & DMF & $t$-BuOK & 3 & Air & $1 \mathrm{~h}$ & $75 \%$ \\
\hline
\end{tabular}

Reaction conditions: All reactions performed in a $20 \mathrm{~mL}$ scintillation via, $1 \mathbf{a}(0.025 \mathrm{M}), 2.5 \mathrm{~mL}$ of solvent, $4 \AA$-molecular sieves (MS), and room temperature $\left(22^{\circ} \mathrm{C}\right)$. All yields determined by ${ }^{1} \mathrm{H}$ NMR using internal standard.

We then explored the scope of substituents that are compatible with the reaction conditions. Variation in the pendant aryl ring revealed that heterocyclic substrates, as well as the substrates with ortho, meta, and para electron withdrawing groups produced the target products in good to excellent yields. On the other hand, electron donating groups were only tolerated in the meta position. Lower conversions to the corresponding isoindolinone were observed (39\% and $48 \%$ respectively) for the reactions of 4-methoxy and 4-methyl substrates. However, substrate 2c with a para tert-butyl group underwent the desired transformation in high yield (84\%).

Substitution in the amide ring had a smaller effect - reaction tolerated both electron donating and withdrawing groups, ortho, meta, and para to the amide. The overall transformation remained unaffected with halogens (i.e., $\mathrm{Br}, \mathrm{Cl}$, and $\mathrm{F}$ ) on either the amide ring or pendant aryl ring, allowing for the introduction of a useful synthetic handle for future modifications.

We also investigated the possibility of introducing additional substituents at the amide nitrogen. The N-methyl amide $2 \mathbf{r}$ underwent the desired transformation sluggishly (30\% yield, $74 \%$ based on reclaimed starting material) under the standard conditions. On the other hand, a Nmethoxy amide remained unreactive under our standard conditions (vide infra). 
Table 2. Amide scope for $\mathrm{C}\left(\mathrm{sp}^{3}\right)-\mathrm{H}$ amidation and hydroxylation.
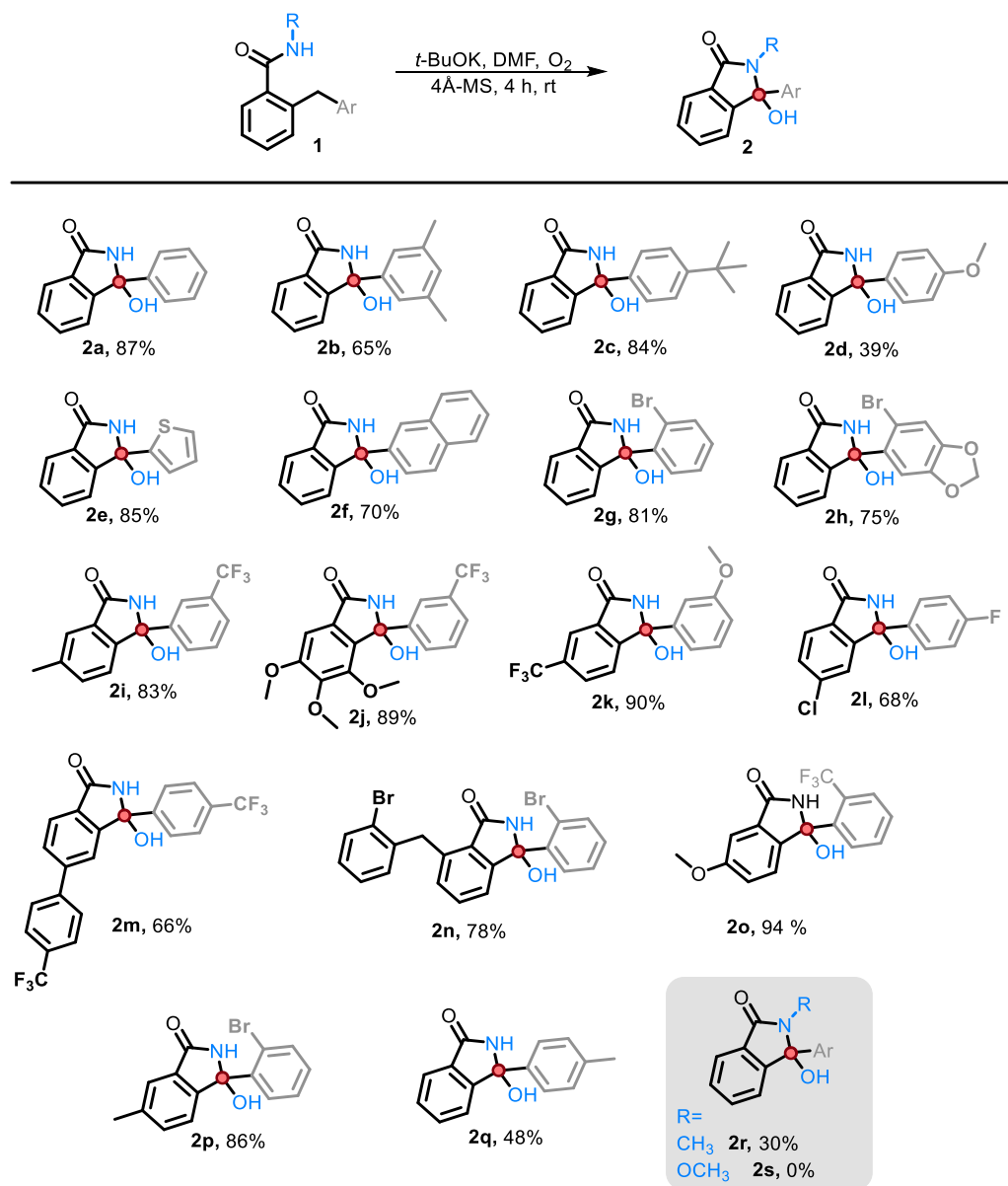

Reaction conditions: benzamide $(0.025 \mathrm{M}), t$-BuOK (3 eq.), $4 \AA \mathrm{MS}, \mathrm{DMF}, \mathrm{O}_{2}$ balloon and the reactions were allowed to stir for 4 hours at rt. Unless stated otherwise, the yield is of the isolated product.

\section{Mechanistic studies}

A series of studies designed to gain insight into the reactions mechanism were performed and are listed below (Scheme 5). First, the $\mathrm{C}-\mathrm{H}$ bond strength is critical for the reaction success. A BDE $\leq 85 \mathrm{kcal} / \mathrm{mol}$ was needed and simple benzylic or alkylbenzylic $\mathrm{C}-\mathrm{H}$ bonds remained unreactive under our conditions (Eq. 1).

When the reaction is performed under an inert atmosphere (Ar), the consumption of $\mathbf{1 a}$ is greatly diminished (Eq. 2), confirming the importance of $\mathrm{O}_{2}$ as the oxidant.

We have also considered the possible involvement of singlet oxygen. Singlet oxygen has been shown to be synthetically useful in the oxidation of heteroatoms, cyclization reactions, and the synthesis of hydroperoxides. ${ }^{25}$ However, $\mathbf{1 i}$ was fully consumed even in the absence of light, producing $\mathbf{2 i}$ in $79 \%$ yield (Eq. 3). Reactivity in the dark indicates that singlet oxygen is not involved in the main path of this reaction. 


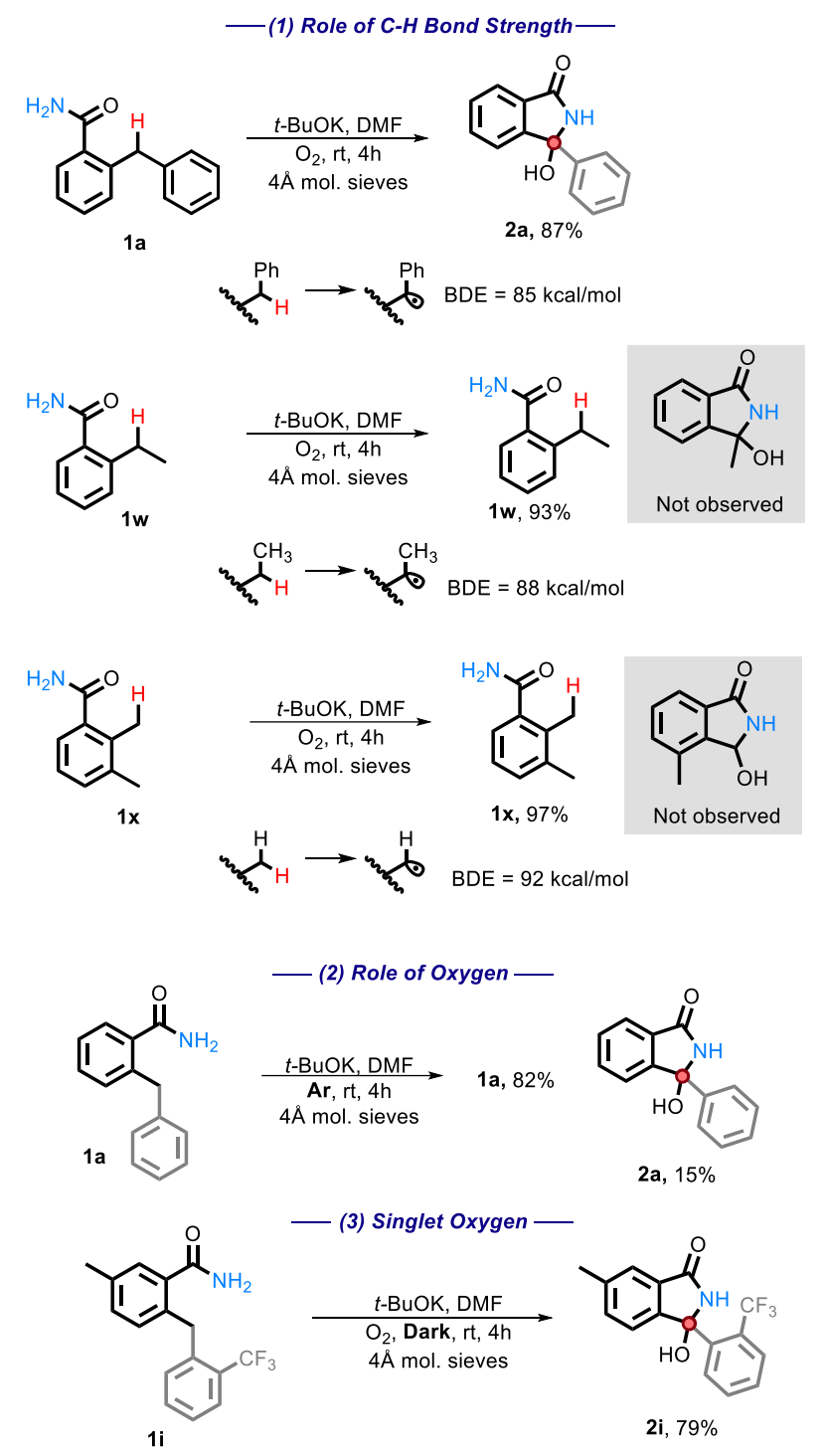

Scheme 5: Mechanistic studies for C-H bond strength and the participation of oxygen. All energies are reported in $\mathrm{kcal} / \mathrm{mol}$.

Under these oxidative conditions, one could suggest that the reaction occurs via an oxidation of the $\mathrm{CH}_{2}$ moiety to a carbonyl intermediate. ${ }^{26}$ This intermediate could then close the cycle via nucleophilic attack of the amide onto the carbonyl under basic conditions. We have eliminated benzylic C-H oxidation in our early work by using N-Me substituted anilines, which yield products that clearly could not originate from the ketone. ${ }^{10}$ Obtaining such direct evidence in the present case is problematic because, unlike the aniline cascade, the present amide cascade is terminated by $\mathrm{C}-\mathrm{O}$ bond formation that renders the $\mathrm{C} / \mathrm{N}$ radical-anion coupling and the carbonyl pathway products identical. 

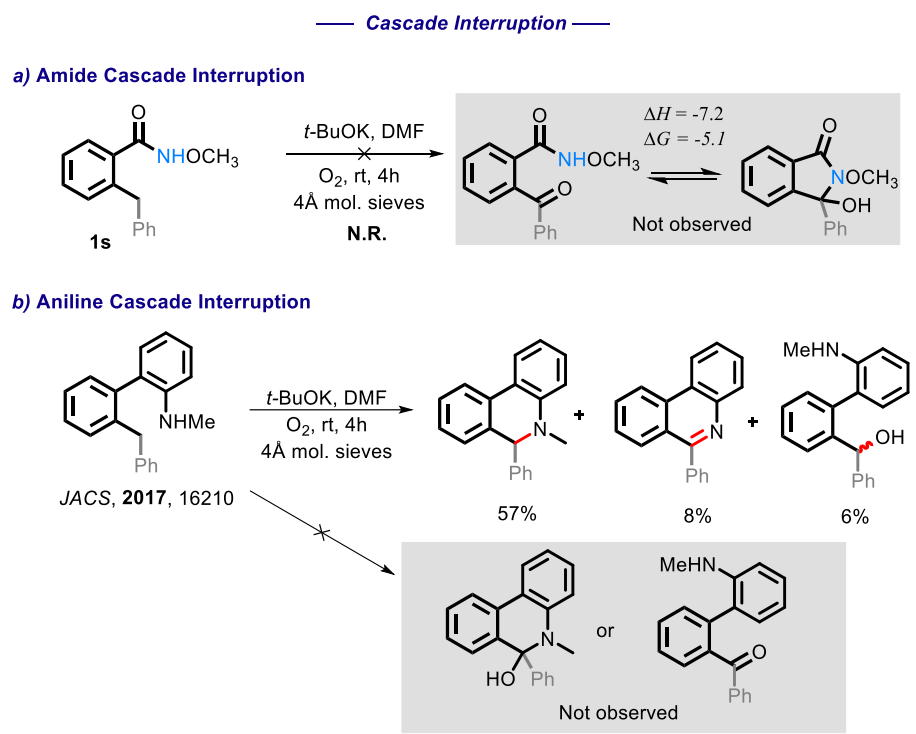

Scheme 6. Interruption of the amide and aniline cascades

To test for the possibility of a carbonyl intermediate we wanted to use an amide that would lack reactivity and interrupt the cascade cyclization, while still allowing for the benzylic carbon to remain reactive enough to be oxidized into a ketone. However, addition of $\mathbf{1 s}$ to our standard conditions resulted in no reaction occurring. Calculations show that if a ketone intermediate were formed, its cyclization would be thermodynamically favorable $(\Delta \mathrm{G}=-5.1 \mathrm{kcal} / \mathrm{mol})$. Assuming that this substitution at nitrogen does not directly change reactivity at the remote benzylic position, the lack of cyclization or benzylic oxidation suggests that the carbonyl intermediate is not formed under our conditions ${ }^{10}$ (Scheme 6).

\section{Computational Data}

Calculations were carried using the meta-hybrid (U)M06-2X functional ${ }^{27}$ and the 6$31+\mathrm{G}(\mathrm{d}, \mathrm{p})$ basis set for all atoms, with an ultrafine integration grid (99,590 points). A broken-spin approach was applied when necessary. The implicit $\mathrm{SMD}^{28}$ solvation model was used to simulate the effects of N,N-dimethyl-formamide (DMF) throughout the calculated structures. Grimme's D3 version (zero damping) for empirical dispersion ${ }^{29}$ was also included. Unless otherwise noted, all results presented are at the $(\mathrm{SMD}=\mathrm{DMF}) /(\mathrm{U}) \mathrm{M} 06-2 \mathrm{X}(\mathrm{D} 3) / 6-31+\mathrm{G}(\mathrm{d}, \mathrm{p}) /$ int=ufine level of theory. Frequency calculations were carried for all structures to confirm them as either a minimum or a TS. All calculations were performed with the Gaussian 09 software package. ${ }^{30}$ Structural drawings and orbital plots were produced with CYLView 1.0.1 ${ }^{31}$ and Chemcraft $1.8 .^{32}$

\section{Radical Cascade Mechanism}

Guided by these experimental results, we turned to computations for identifying the key intermediates of this transformation. Full thermodynamic landscape for the proposed reaction cascade is shown in Scheme 7. Each step in this cascade is thermodynamically favorable. In subsequent individual sections, we will discuss the individual steps along with the respective experimental evidence. 


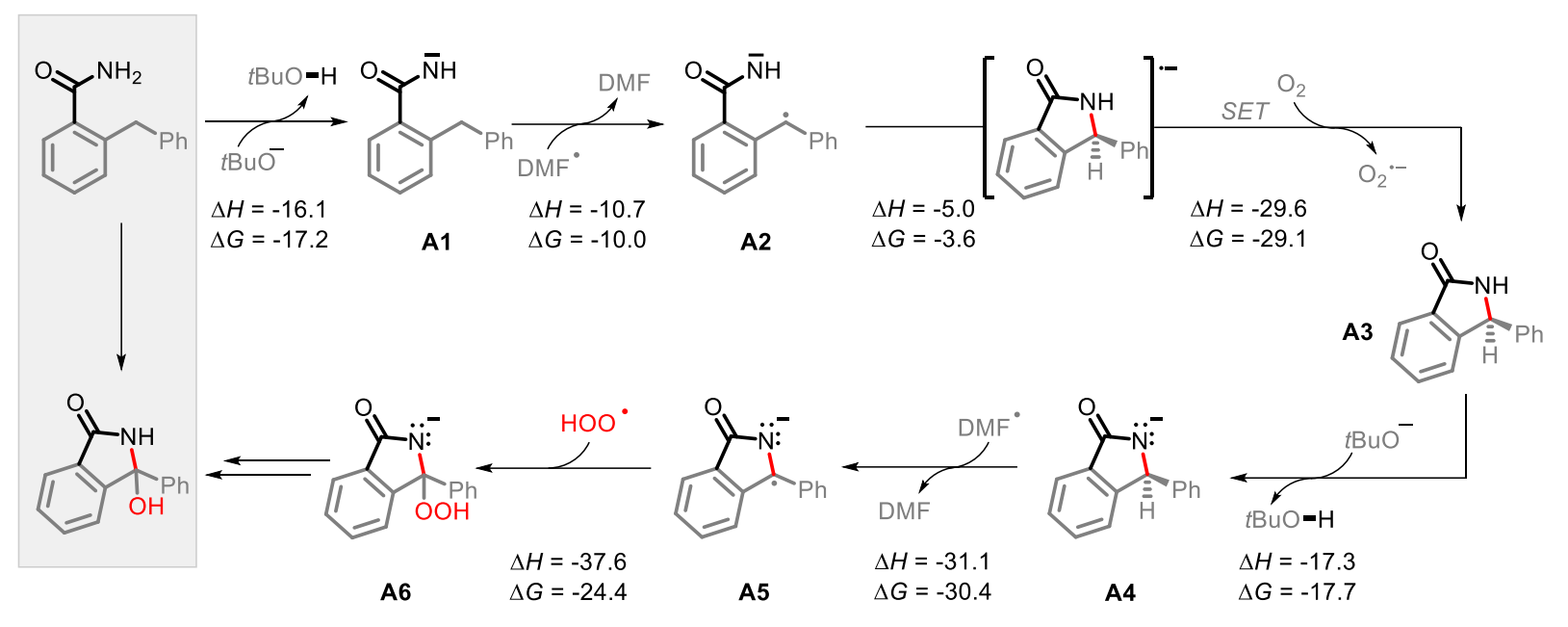

Scheme 7. Proposed mechanism and calculated reaction thermodynamics for the individual steps in the $\mathrm{N}-\mathrm{H} / \mathrm{C}-\mathrm{H}$ amidation. All energies are in $\mathrm{kcal} / \mathrm{mol}$.

\section{Deprotonation/ H-Atom Transfer}

The unusual nature of our intramolecular $\mathrm{C}-\mathrm{H}$ amination stems from the generation of a radical and an anion in situ. To achieve this, two criteria must be met. First, an acidic proton is needed for a deprotonation that produces a persistent $\mathrm{N}$-anion. Second, the substrates should have a sufficiently weak $\mathrm{C}-\mathrm{H}$ bond that undergoes HAT with the formation of a C-radical.

The cascade mechanism begins with the deprotonation of the mildly acidic benzamide by tert-butoxide, $\Delta \mathrm{G}=-17.2$ (Scheme 7, A1). Following the generation of a persistent nitrogen anion, the bis-benzylic $\mathrm{C}-\mathrm{H}$ bond $(\mathrm{BDE}=85 \mathrm{kcal} / \mathrm{mol})$ is sufficiently weak to engage in a HAT with DMF radical (see the SI for discussion of DMF radical formation), $\Delta \mathrm{G}=-10.0 \mathrm{kcal} / \mathrm{mol}$ (Scheme 7 , A2). This step yields a relatively stable $\mathrm{C}$-centered radical and our initial radical-anion intermediate. While the HAT $\Delta \mathrm{G}^{*}$ and $\Delta \mathrm{G}$ are slightly lower for the neutral amide than the deprotonated amide $\left(\Delta \mathrm{G}^{\ddagger}=17.6 \mathrm{vs} 19.1, \Delta \mathrm{G}=-10.9 \mathrm{vs}-10.0 \mathrm{kcal} / \mathrm{mol}\right)$, the higher concentration of base and the overall thermodynamically favored deprotonation step will result in HAT occurring after deprotonation (Scheme 8).

Upon further inspection, our calculations show an interesting transition state for the initial HAT. At stage where the benzylic $\mathrm{C}-\mathrm{H}$ bond begins to break to form the $\mathrm{C}$-centered radical, the benzylic $\mathrm{C}-\mathrm{H}$ is misaligned with the aromatic $\pi$-system. Hence, the forming radical finds itself in alignment only with the pendant aromatic ring. One might expect that as this radical would prefer to be in a close alignment with both aromatic rings to take advantage of stereoelectronic stabilization. This finding explains why the pendant aryl group is necessary - although the $\mathrm{CH}_{2}$ groups in substrates $\mathbf{1 w}$ and $\mathbf{1} \mathbf{x}$ are formally "benzylic" (Scheme 5), the core aryl group does not directly contribute to their $\mathrm{C}-\mathrm{H}$ activation. Under these intramolecular stereoelectronic constraints, their relatively low $\mathrm{BDE}$ values are somewhat misleading.

Furthermore, the amide is rotated out of conjugation the aromatic $\pi$-system in a nearly orthogonal geometry. ${ }^{33}$ Steric hindrance between the two relatively large ortho-substituents contributes to this geometric preferences. In addition, the electron cloud of the amide may have substantial through-space interactions with the back lobe of the anti-bonding orbital of the breaking 
$\mathrm{C}-\mathrm{H}$ bond. In other words, the amide may be assisting in the $\mathrm{C}-\mathrm{H}$ activation process by helping to stabilize the newly forming radical via a through-space interaction.

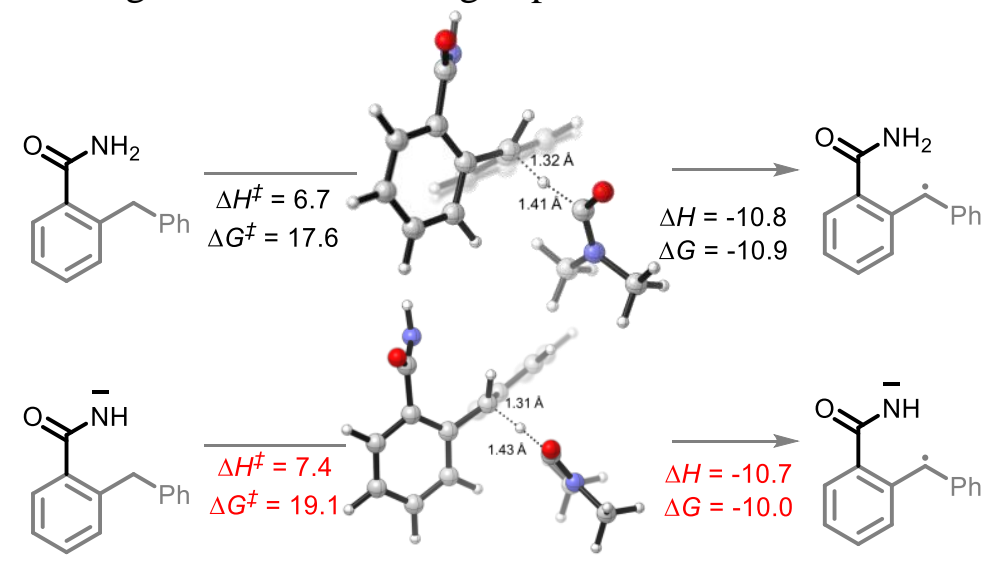

Scheme 8. Reaction energy profiles and twisted transition states for C-H activation in neutral and deprotonated substrates. All energies are in $\mathrm{kcal} / \mathrm{mol}$.

\section{Radical-Anionic Cyclization and C-N Bond Formation}

The $\mathrm{N}$-anion and the $\mathrm{C}$-centered radical in $\mathbf{A} 2$ react to form a $2 c, 3 e$ "half" bond, also making a cyclic radical-anion in the process. Interestingly, this process occurs without the apparent loss of amide resonance since it is the $2^{\text {nd }}$ "in-plane" lone pair of nitrogen that is involved in the $\mathrm{N}-\mathrm{C}$ coupling. On the other hand, the radical center rotates out of conjugation with the central aryl ring as well. The latter stereolectronic penalty is likely to account for a relatively high, 17.2 $\mathrm{kcal} / \mathrm{mol}$, Gibbs barrier and the low thermodynamic driving force, $\Delta \mathrm{G}=-3.6 \mathrm{kcal} / \mathrm{mol}$, for this seemingly trivial step (Scheme 9).

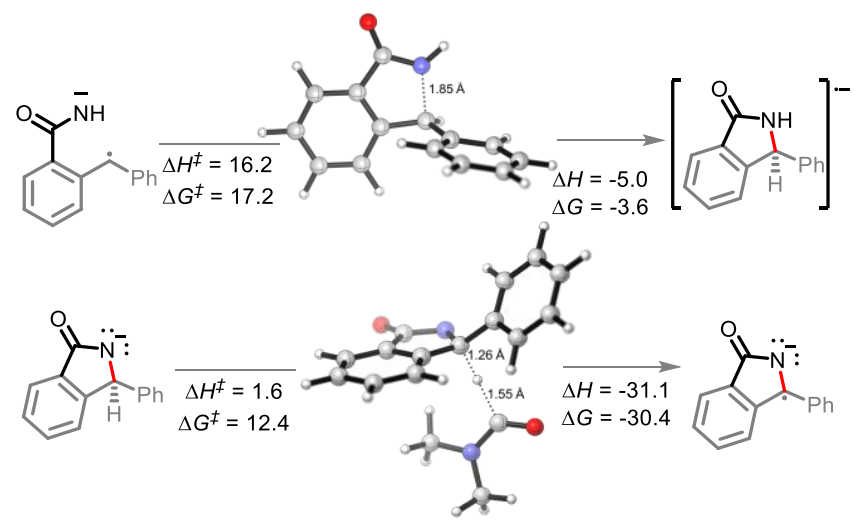

Scheme 9. Transition states for the C-N bond formation and second HAT.

Additionally, the three non-bonding electrons of the radical and anion reacting partners have to find "a new home" in this step. Two of these electrons are accommodated in the newly formed $\sigma$ orbital of the $\mathrm{C}-\mathrm{N}$ bond. The third electron avoids its apparent destiny of ending up at the high energy $\sigma^{*}{ }_{\mathrm{C}-\mathrm{N}}$ orbital by "hopping" to a lower energy $\pi^{*}$ orbital of the aromatic ring 
(Scheme 10). This state crossing, not unusual for radical-anionic reactions, ${ }^{34}$ stabilizes the product by creating a delocalized $\pi$-type radical-anion.

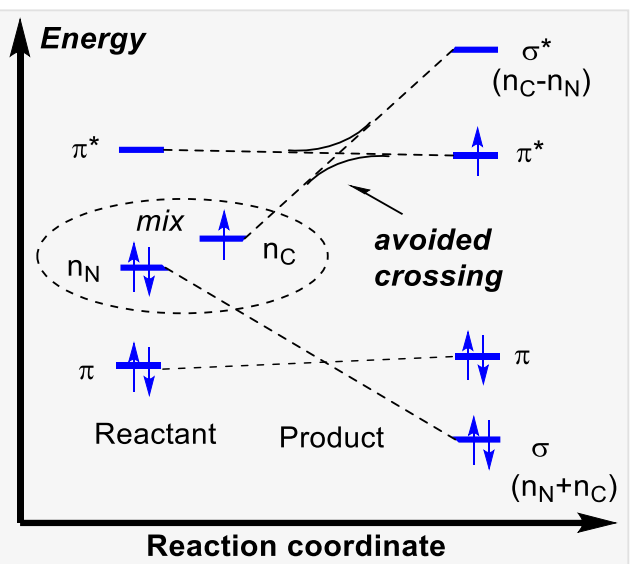

Scheme 10. State crossing avoids populating the high energy $\sigma^{*} \mathrm{C}-\mathrm{N}$ orbital.

Nevertheless, the $2 c, 3 e$-bond reactant is evolved from a mild reductant (electron in a nonbonding orbital) into a more potent reductant (electron is an antibonding orbital). The high reducing power of the cyclic product allows its reaction with a mild oxidant, such as molecular oxygen. This reaction (i.e., single electron transfer) removes the antibonding electron, converting a $2 c, 3 e$-bond into a normal $2 c, 2 e \mathrm{C}-\mathrm{N}$ bond. This step simultaneously forms superoxide in a thermodynamically favorable way with $\Delta \mathrm{G}=-29.1 \mathrm{kcal} / \mathrm{mol}$ (Scheme $7, \mathbf{A 3}$ ).

After the benzamide is cyclized into an isoindolinone, the cyclic intermediate is deprotonated to give anion $\mathbf{A 4}$ (Scheme 7, $\Delta \mathrm{G}=-17.7 \mathrm{kcal} / \mathrm{mol}$ ). The $\alpha-\mathrm{C}-\mathrm{H}$ bond in this anion is sufficiently weakened to form a stabilized radical-anion $\mathbf{A 5}$ ( $\Delta \mathrm{G}=-30.4 \mathrm{kcal} / \mathrm{mol}$ after a HAT to DMF radical).

\section{Diverting from $\mathrm{C}=\mathrm{N}$ to $\mathrm{C}-\mathrm{O}$ bond formation}

From the stabilized radical intermediate A5, one can envision two possible mechanistic routes for the formation of the $\mathrm{C}-\mathrm{O}$ bond (Scheme 11). The first possibility is similar to what we reported in our previous work ${ }^{10}$, in which the intermediate is oxidized a second time by molecular oxygen to form the $\mathrm{C}=\mathrm{N}$ moiety of an imine intermediate. This intermediate may then be intercepted by a suitable nucleophile generated in situ, such as superoxide or hydroxide. In particular, superoxide is known to undergo disproportionation to give $\mathrm{O}_{2}$ and hydroxide under aqueous conditions. ${ }^{35}$ It is possible that a similar process to generate hydroxide could occur under the conditions of our $\mathrm{C}-\mathrm{H}$ amination reaction, whereas $t$ - $\mathrm{BuOH}$ would be our proton source instead of $\mathrm{H}_{2} \mathrm{O}$. The second possibility, is that a radical coupling partner such as superoxide or hydroperoxyl radical may couple to the $\mathrm{C}$-centered radical making a hydroperoxide intermediate. 


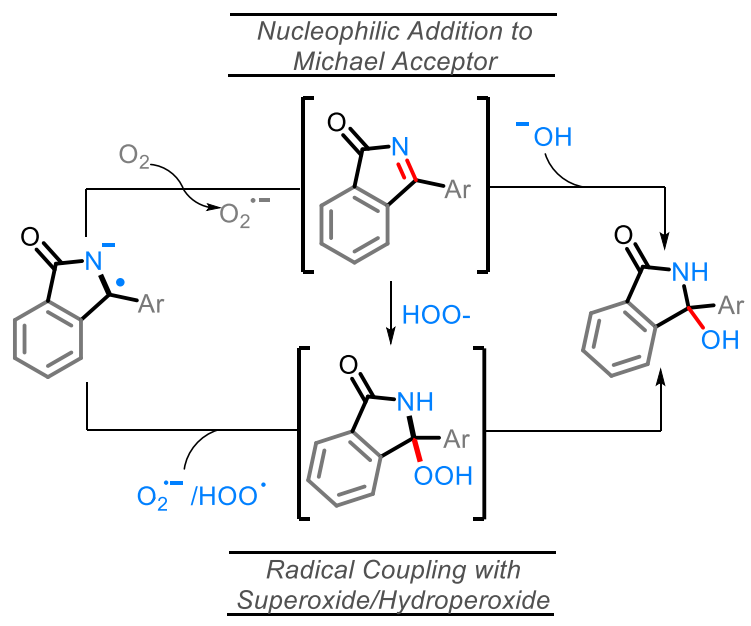

Scheme 11. Possible routes to product from stabilized radical-anion intermediate.

We initially tested to see if the addition of an external nucleophile could be used to trap the plausible imine intermediate. The addition of either sodium or potassium methoxide hinders the reaction, with no methoxy product observed in these experiments (Scheme 12).

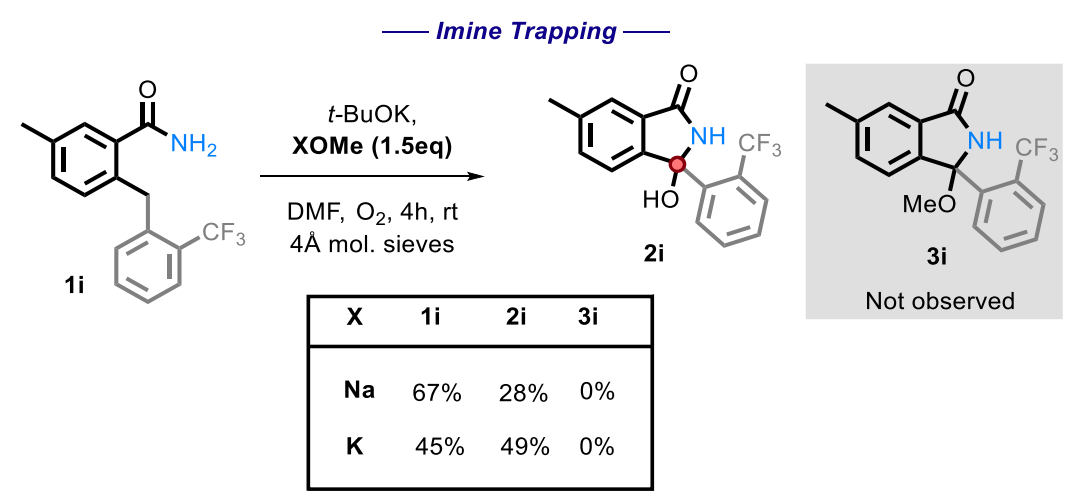

Scheme 12. Attempting to trap the hypothetical imine intermediate.

Our calculations show the oxidation of $\mathbf{A 5}$ by $\mathrm{O}_{2}$ is thermodynamically uphill $(\Delta \mathrm{G}=+10.0$ $\mathrm{kcal} / \mathrm{mol}$, Scheme 13). While this is not a prohibitive price to pay, it is worth noting that this oxidation step is $39.1 \mathrm{kcal} / \mathrm{mol}$ more endergonic than the initial oxidation step. This substantial increase stems from several factors, including lack of aromatic stabilization in the N-heterocyclic part as well as the additional radical and charge stabilization, not only through the bis-phenyl groups, but additionally through the nitrogen and carbonyl.

This finding contrasts our previous work with anilines where the second oxidation step was favorable $(\Delta \mathrm{G}=-16.6 \mathrm{kcal} / \mathrm{mol})$ due to the formation of an aromatic system. ${ }^{10}$ In the present case, the situation is different and this differences manifests itself in a divergent reaction pathway (formation of a $\mathrm{C}-\mathrm{O}$ bond instead of $\mathrm{C}=\mathrm{N}$ moiety). In order to understand this step better, we explored the possibility of radical coupling being responsible for the final $\mathrm{C}-\mathrm{O}$ formation. 


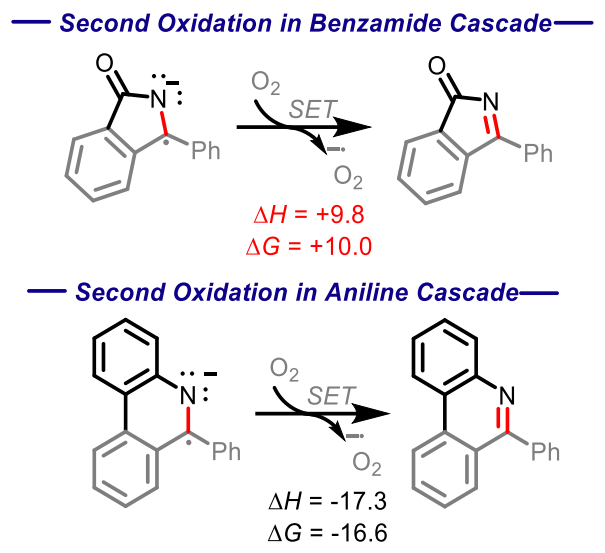

Scheme 13. Contrasting thermodynamics $(\mathrm{kcal} / \mathrm{mol})$ for the $\mathrm{C}=\mathrm{N}$ forming oxidations in the amide and aniline cascades

A series of studies designed to gain insight into the possible radical coupling of A5 were performed and are listed below (Scheme 14).

We then employed the use of two common radical trapping agents, attempting to either trap a radical intermediate or to inhibit the reaction. In the case of TEMPO, there was a slight decrease in isolated yield (87\% vs 76\%) but, no TEMPO trapped product or recovered starting material was observed (Eq. 1). This finding is consistent with the radical mechanism if intramolecular radical trapping (i.e., the cyclization) is faster than the intermolecular trapping, or if TEMPO can play an alternative role by promoting the $\mathrm{C}-\mathrm{H}$ activation step. More detailed discussion on the possible role of TEMPO will be given in a subsequent section.

We also tested the effect of a common radical and peroxide trapping agent, 3,5-di-tert-4butylhydroxytoluene (BHT), at the standard reaction conditions (Eq. 2). The phenol moiety of BHT is often used to halt the autoxidation of organic molecules with oxygen, analogous to that of vitamin E. BHT can deactivate two (usually peroxy) radicals - the first one by a hydrogen atom transfer and the second one by reaction at the cycle. ${ }^{36}$

We found that the reaction is partially inhibited ( $2 \mathbf{i}$ was isolated in a $47 \%$ yield, starting material recovered in $27 \%$ isolated yield. Furthermore, BHT-OH was additionally isolated, $25 \%$ yield (low yields are a result of isolation difficulties). Formation of this product further suggests that a radical pathway is involved.
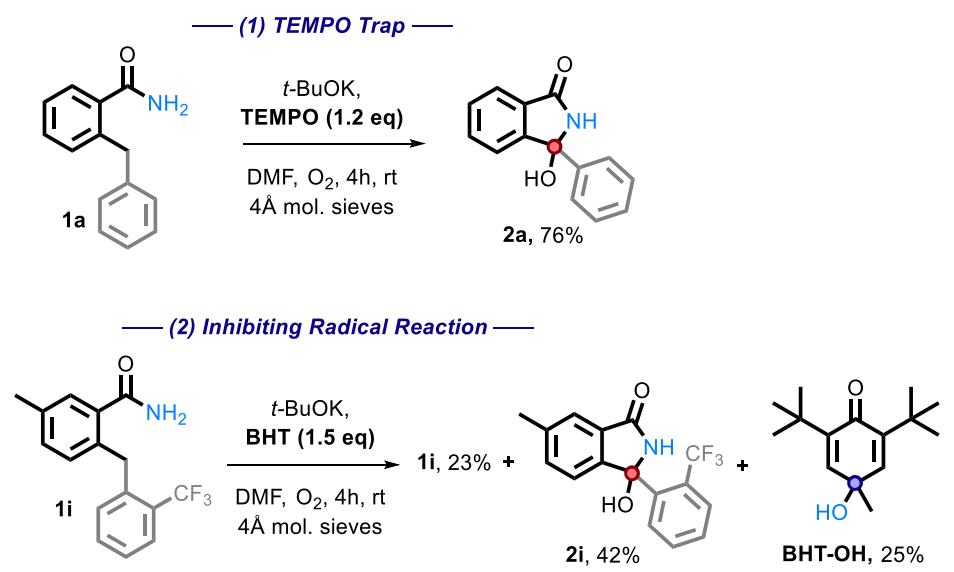

Scheme 14. Radical coupling mechanistic studies. ${ }^{\text {a }}$ Yield determined by NMR. 


\section{Addition of Superoxide/Hydroperoxyl Radical to the Radical-Anion A5}

It is unlikely that the $\mathrm{OH}$ group in the final product is a result of radical coupling with hydroxide radical, as it is highly reactive and will likely abstract a hydrogen atom from the solvent or $t$ - $\mathrm{BuOH}$ before reaching the reactant. ${ }^{37}$ This consideration led us to explore the possibility of radical coupling with superoxide, or with its conjugate acid, i.e., the hydroperoxyl radical $(\mathrm{HOO} \bullet)^{38}$

Our calculations show this to be a favorable path for forming the C-O bond (Scheme 15). In particular, radical addition to intermediate $\mathbf{A 5}$ via $\mathrm{HOO} \bullet$ was found to be highly exergonic, $\Delta \mathrm{G}$ $=-23.6 \mathrm{kcal} / \mathrm{mol}$. Addition of superoxide (the precursor of $\mathrm{HOO} \bullet$ ) to $\mathbf{A 5}$ was favorable, $\Delta \mathrm{G}=$ $11.0 \mathrm{kcal} / \mathrm{mol}$. On the other hand, the addition of molecular oxygen was found to be endergonic, $\Delta \mathrm{G}=+7.5 \mathrm{kcal} / \mathrm{mol}$. It is worth noting that all three of these proposed pathways are thermodynamically more favorable than an oxidation of $\mathbf{A 5}$ by $\mathrm{O}_{2}(\Delta \mathrm{G}=+10.0 \mathrm{kcal} / \mathrm{mol})$.

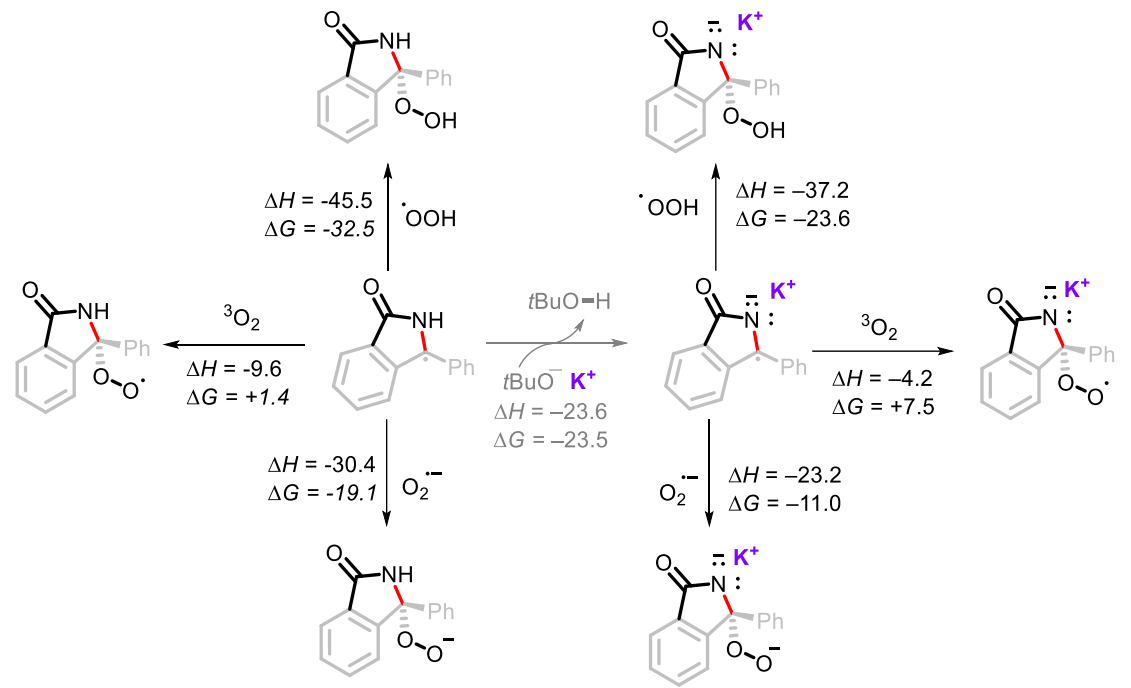

Scheme 15. Computational thermodynamic data for the addition of molecular oxygen, superoxide, and hydroperoxyl radical to the stabilized radical intermediate. Energies in $\mathrm{kcal} / \mathrm{mol}$.

Superoxide has been shown to act as a Brønsted base in aprotic media and deprotonate weak acids such as 1-butanol in DMF $\left(\mathrm{pKa}=33.3\right.$ in DMF) ${ }^{39}$. It is therefore possible, that superoxide may deprotonate t-BuOH (estimated $\mathrm{pKa} \approx 34-35$ in $\mathrm{DMF}$ ) generated in situ, forming HOO•. Hence, both HOO• and superoxide may couple with A5.

The evidence that we have presented up to this point suggests that formation of a hydroperoxide intermediate ${ }^{40}$ should be considered (Scheme 7, A6). In order to explore this possibility, we have prepared this intermediate and tested its properties as described in the following section.

\section{Hydroperoxide Intermediate}

The hydroxy group of $\mathbf{2 p}$ was converted into hydroperoxy group of $\mathbf{3 p}$ (Scheme 16, Eq 1) by acid-catalyzed reaction with $\mathrm{H}_{2} \mathrm{O}_{2}$. The reference spectra contained the characteristic broad downshifted peak of a hydroperoxide that readily underwent deuterium exchange. ${ }^{41}$ After subjecting $3 \mathbf{p}$ to our standard conditions the formation of $\mathbf{2 p}$ could be seen via TLC within five 
minutes, the reaction was left to proceed for half an hour and $\mathbf{2 p}$ was obtained in $88 \%$ yield (Scheme 16, Eq 2). The lack of $\mathbf{3 p}$ reactivity in the absence of $t$-BuOK (Scheme 16, Eq 2) indicates the important role of $t$-BuOK in the reduction of the hydroperoxide intermediate into the final product.

Because of the rapid consumption of hydroperoxide in the presence of base, we anticipate its existence in situ to be fleeting. The existence of transient hydroperoxide intermediates, that convert to an $\mathrm{OH}$-bearing final products, has previously been reported in $\mathrm{O}_{2}$-mediated oxidations of $\mathrm{C}\left(\mathrm{sp}^{3}\right)-\mathrm{H}$ bonds. ${ }^{42}$ Indeed, in several experiments, ${ }^{1} \mathrm{H}$ NMR of the reaction mixtures showed a broad downshifted singlet, potentially indicative of the hydroperoxide (See Supporting Information for additional details). Although this intermediate was too unstable to persist and to be reliably detected under the reaction conditions, these findings suggest that a hydroperoxide intermediate (Scheme 7, A6) is formed transiently and reduced by $t-\mathrm{BuOK} / t-\mathrm{BuOH}$ into the final isoindolinone product.

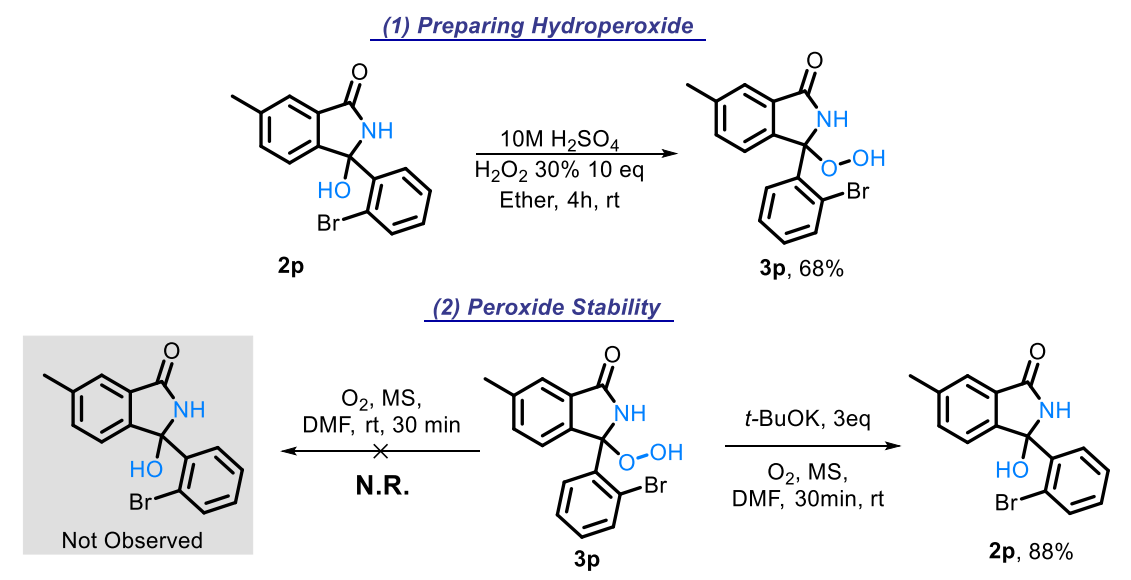

Scheme 16. Preparation and instability of the suggested hydroperoxide intermediate.

\section{Secondary Amides}

We were intrigued by the sluggish reactivity of the secondary amides. Since we get back the unreacted starting material, the reaction is stalling out in the initial stages of the reaction. Yet our thermodynamic calculations find that each of the three initiation steps, i.e., the deprotonation $(\Delta \mathrm{G}=-16.0)$, HAT $(\Delta \mathrm{G}=-9.3)$, and the radical-anion cyclization $(\Delta \mathrm{G}=-5.9)$, for $\mathbf{1 r}$ are thermodynamically favorable (Scheme 17).

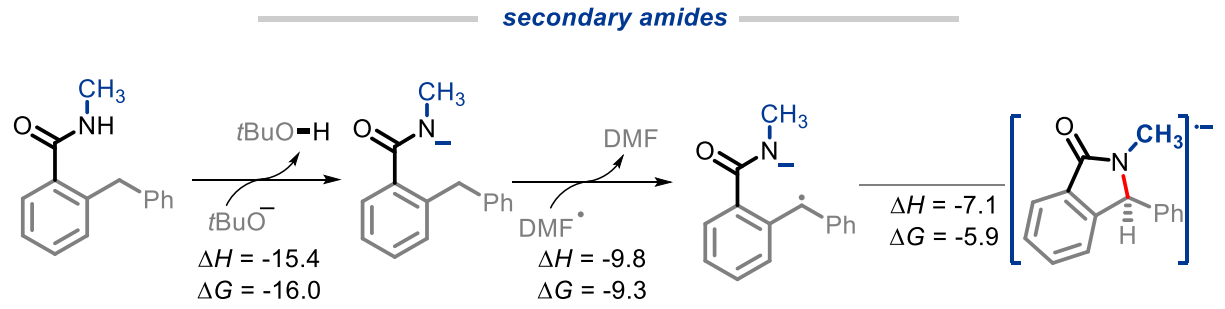

Scheme 17. Thermodynamic calculations for the deprotonation, HAT, and radical-anion cyclization of $\mathbf{1 r}$. All energies are reported in $\mathrm{kcal} / \mathrm{mol}$. 
We used computed activation barriers to understand why the secondary amides are unreactive (See Supporting Information). Our analysis suggests that the barrier for the $\mathrm{H}$ abstraction is about $1.2 \mathrm{kcal} / \mathrm{mol}$ higher for the secondary amides than it is for the primary amides. Such difference in the barrier should correspond to a ca. 10-fold rate decrease for this step, providing a possible explanation for the low reactivity of the secondary amide substrates under the reaction conditions.

Conversely, the calculated barrier for the $\mathrm{C}-\mathrm{N}$ bond formation is lower for the secondary amides, indicating that this step is unlikely to be the cascade bottleneck (Scheme 18). Aimed by these observation, we have concentrated our attention on the H-transfer step.

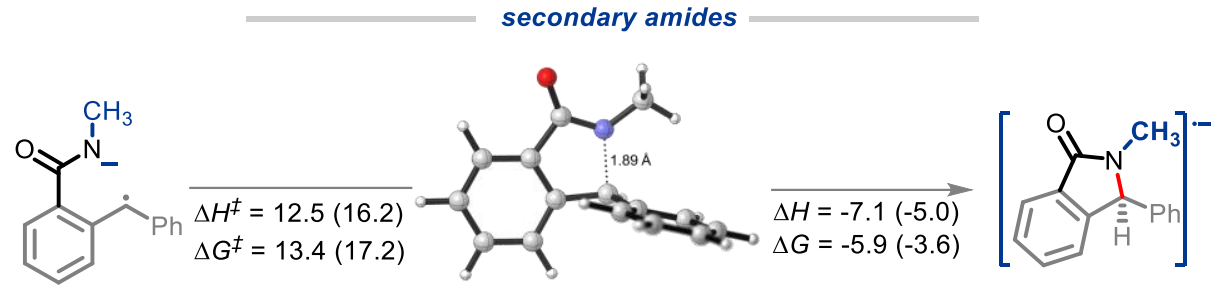

Scheme 18. Computed activation and reaction enthalpies and Gibbs energies for the cyclization of secondary amide 1r. Numbers in parenthesis are for primary amide 1a. All numbers reported in $\mathrm{kcal} / \mathrm{mol}$.

Indeed, focus on $\mathrm{C}-\mathrm{H}$ activation allowed us to solve the problem of secondary amides as described below. Recalling that TEMPO had no detrimental effect on our radical reaction, we decided to consider the possibility of TEMPO assisting in $\mathrm{C}-\mathrm{H}$ activation.

Indeed, literature suggests that TEMPO can be a useful additive to the oxidation of benzylic $\mathrm{C}\left(\mathrm{sp}^{3}\right)$-H's. For example, TEMPO can be oxidized into an oxoammonium salt (TEMPO+) in the presence of hydroperoxyl radical, peroxyl radicals, or a secondary oxidant (e.g. $\mathrm{NaOCl}$ ) as shown in Scheme 19a. ${ }^{43}$ The latter has been shown to act as an oxidant that may facilitate the forward progression of redox reactions. ${ }^{44}$ In particular, TEMPO+, generated in situ, from TEMPO was used as a cocatalyst in the aerobic oxidation of benzylic $\mathrm{C}\left(\mathrm{sp}^{3}\right)-\mathrm{H}$ into carbonyls. ${ }^{45}$ Even if the carbonyl intermediate is formed in this case, it would, as we previously discussed in Scheme 6, readily cyclize under basic conditions into our isoindolinone product.

Additionally, TEMPO+ has been suggested to facilitate benzylic hydride transfers. ${ }^{46}$ It is plausible that in our case, a concerted $\mathrm{C}-\mathrm{N}$ bond formation and benzylic hydride transfer to TEMPO+ occurs generating TEMPOH and our cyclized product (Scheme 19b). Alternatively, one can consider a hydride transfer to TEMPO+ forming a benzylic carbocation that is immediately trapped intramolecularly via cyclization (Scheme 19c). 
a) Redox activation of TEMPO

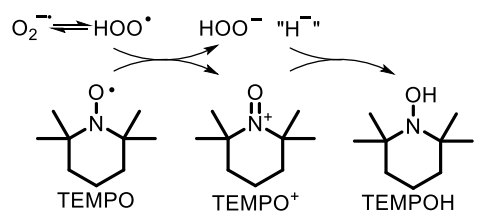

b) Concerted Cyclization and Hydride Transfer

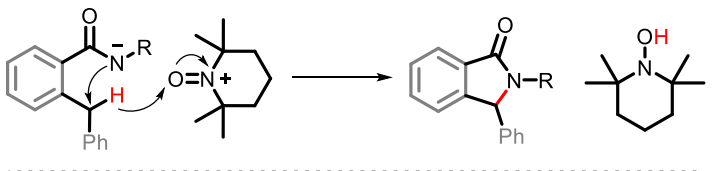

c) Hydride Transfer and Zwitterion Cyclization<smiles>[R]NC(=O)c1ccccc1C(CCO[N+]1(C)C(C)(C)CCCC1(C)C)c1ccccc1C(=O)N[R]</smiles><smiles>[R]NC(=O)c1ccccc1[PH2+]c1ccccc1C1c2ccccc2C(=O)N1[R]</smiles>

Scheme 19. Potential pathways for TEMPO assistance in C-H activation.

Although the exact mechanistic path for $\mathrm{C}-\mathrm{H}$ activation in our system is so far unknown, the combination of possible attractive scenarios motivated us to test the effect of TEMPO on the reaction. To our delight, we observed the nearly full consumption when secondary amide 1r was subjected to the optimized conditions along with TEMPO (1 eq.). Interestingly, no TEMPOtrapping product was present in the reaction mixture. Instead, $\mathbf{2 r}$ was obtained in $74 \%$ isolated yield - a dramatic improvement over the standard conditions (30\% without TEMPO vs. $74 \%$ with TEMPO, Scheme 20). Motivated by this finding, we tested reactivity of $\mathbf{1 s}$ in the presence of TEMPO. Gratifyingly, the reaction affords $2 \mathbf{s}$, albeit in a moderate yield of $31 \%$ (the majority of reaction mixture is unreacted $\mathbf{1 s}$ ). Furthermore, substrates $\mathbf{1 t}, \mathbf{1} \mathbf{u}$, and $\mathbf{1 v}$ also showed a substantial increase in reactivity with the addition of TEMPO and the products $\mathbf{2 t}, \mathbf{2} \mathbf{u}$, and $\mathbf{2 v}$ were isolated in $87 \%, 54 \%$, and $55 \%$ respectively.

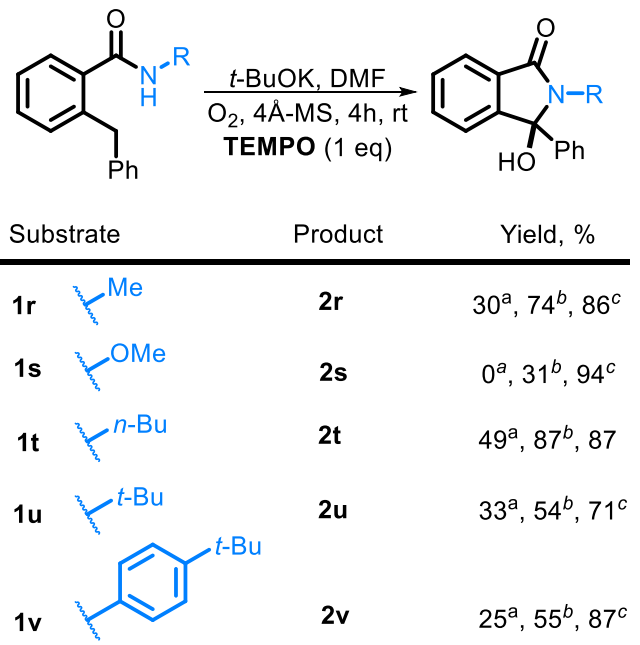

Scheme 20. Improved $\mathrm{C}-\mathrm{H}$ activation with TEMPO as an additive. Reaction conditions:

Secondary benzamide $(0.025 \mathrm{M}), t$-BuOK (3 eq), DMF (2 mL), $4 \AA$ MS, $\mathrm{O}_{2}$ balloon, reactions 
stirred at r.t. overnight. (a) Isolated yields for reaction performed under standard conditions. (b) Isolated yields for reactions with the addition of TEMPO (1 eq). (c) Yields based of reclaimed starting materials with the addition TEMPO (1 eq).

\section{Conclusion}

We have developed a direct method for converting $\mathrm{C}\left(\mathrm{sp}^{3}\right)-\mathrm{H}$ bonds into $\mathrm{C}-\mathrm{N}$ and $\mathrm{C}-\mathrm{O}$ bonds under mild conditions with the aid of base, molecular oxygen and DMF. Each component of the overall reaction has a pivotal role in a coordinated sequence of deprotonation, $\mathrm{H}$-atom transfer, and electron transfer that forges the $\mathrm{C}-\mathrm{N}$ bond. The base has three main functions: 1) to deprotonate the N-H bond, 2) to provide an adequate concentration of DMF carbamoyl anion to be converted to DMF radical, and 3) to convert the hydroperoxide intermediate into the final hydroxyl product. The role of DMF radical is to perform selective HAT at the di-benzylic C $\left(\mathrm{sp}^{3}\right)$ $\mathrm{H}$ that forms a $\mathrm{C}$-centered radical. The $\mathrm{C}-\mathrm{N}$ bond is formed initially through a $2 c, 3 e$ interaction between the $\mathrm{N}$-anion and $\mathrm{C}$-radical. Oxidation of the radical-anion intermediate by oxygen completes the $\mathrm{C}-\mathrm{N}$ bond forming sequence. Computation data suggest that the stabilized radical anion formed after the second HAT could not be oxidized by molecular oxygen. Instead superoxide/hydroperoxide couples with the radical to generate a hydroperoxide intermediate that ultimately decomposes to form the hydroxide product. Addition of TEMPO opens the door for the use of secondary amides and improves the performance of insufficiently reactive primary amides. This process allows for the formation of functionalized N-heterocycles in an operationally simple and robust fashion.

\section{ASSOCIATED CONTENT}

\section{Supporting Information}

Full experimental details, ${ }^{1} \mathrm{H}$ NMR, ${ }^{13} \mathrm{C}$ NMR, HR-MS and NMR spectra for all newly reported compounds and computational details for all calculated structures. The Supporting Information is available free of charge on the ACS Publications website at http://pubs.acs.org.

\section{AUTHOR INFORMATION}

\section{Corresponding Author}

*alabugin@chem.fsu.edu

\section{Notes}

The authors declare no competing financial interests.

\section{Acknowledgments:}

The fundamental and synthetic aspects of this study were supported by donors of the ACS Petroleum Research Fund (PRF\#57377-ND4) and by the National Science Foundation (CHE1465142). We appreciate the allocation of computational resources from FSU RCC and the NSF XSEDE (TG-CHE160006) and assistance in acquiring ${ }^{1} \mathrm{H}$ and ${ }^{13} \mathrm{C}$ NMR spectra from the NMR Facility of FSU Department of Chemistry and Biochemistry. 


\section{TOC Graphic:}

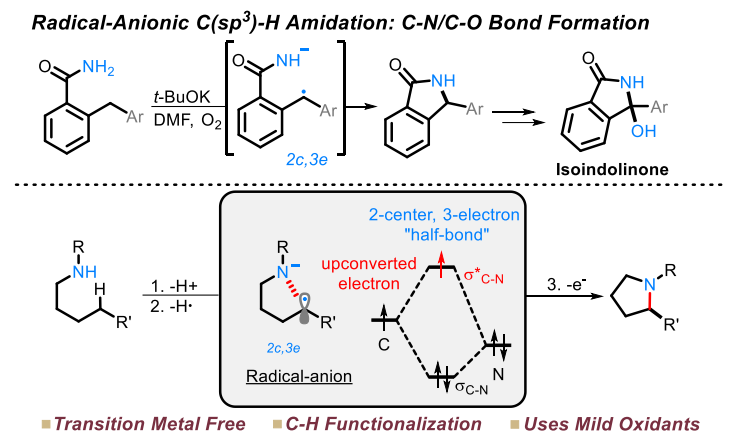

\section{References}

1 (a) Wencel-Delord, J.; Glorius, F. C-H Bond Activation Enables the Rapid Construction and Late-Stage Diversification of Functional Molecules. Nat. Chem. 2013, 5, 389-375. (b) Lu, Q.; Glorius, F. Radical Enantioselective $\mathrm{C}\left(\mathrm{sp}^{3}\right)$-H Functionalization. Angew. Chem. Int. Ed. 2017, 56, 49-51. (c) Choi, G.; Zhu, Q.; Miller. D.C.; Gu, C.; Knowles, R.R. Catalytic Alkylation of Remote C-H Bonds Enabled by Proton-Coupled Electron Transfer. Nature, 2016, 539, 268-271. (d) Chu, J.C.K.; Rovis, T. Amide-Directed Photoredox-Catalysed C-C Bond Formation at Unactivated $\mathrm{sp}^{3} \mathrm{C}-\mathrm{H}$ Bonds. Nature 2016, 539, 272-275. (e) Burg, M. Sc.; Gicquel, M.; Breitenlechner, S.; Pöthig, A. Site- and Enantioselective C-H Oxygenation Catalyzed by a Chiral Manganese Porphyrin Complex with a Remote Binding Site. Angew. Chem. Int. Ed. 2018, 57, 2953-2957. (f) Chu, J.K.; Rovis, T. Complementary Strategies for Directed C $\left(\mathrm{sp}^{3}\right)$-H Functionalization: A Comparison of TransitionMetal-Catalyzed Activation, Hydrogen Atom Transfer, and Carbene/Nitrene Transfer. Angew. Chem. Int. Ed. 2018, 57, 62-101.

2 (a) Peng, B.; Maulide, N. The Redox-Neutral Approach to C-H Functionalization. Chem. Eur. J. 2013, 19, 1327413287. (b) Xie, J.; Pan, C.; Abdukader, A.; Zhu, C. Cold-catalyzed C( $\left.\mathrm{sp}^{3}\right)-\mathrm{H}$ bond functionalization. Chem. Soc. Rev. 2014, 43, 5245-5256. (c) Park, Y.; Kim, Y.; Chang, S. Transition Metal-Catalyzed C-H Amination: Scope, Mechanism, and Applications. Chem. Rev. 2017, 117, 9247-9301. (d) Thansandote, P.; Lautens, M. Construction of Nitrogen-Containing Heterocycles by C-H Bond Functionalization. Chem. Eur. J. 2009, 15, 5874-5883.

3 (a) Chen, M.S.; White, C. Combined Effects on Selectivity in Fe-Catalyzed Methylene Oxidation. Science 2010, 327, 566-571. (b) Murahuashi, S.; Komiya, N.; Nake, T. Aerobic Ruthenium-Catalyzed Oxidative Cyanation of Tertiary Amines with Sodium Cyanide. J. Am. Chem. Soc. 2003, 125, 15312-15313. (b) Dangel, B.; Godula, K.; Won Youn, S.; Sezen, B.; Sames, D. C-C Bond Formation via C-H Bond Activation: Synthesis of the Core of Teleocidin B4. J. Am. Chem. Soc. 2002, 124, 11856-11857. (c) Shabashov, D.; Daugulis, O. Auxiliary-Assisted Palladium-Catalyzed Arylation and Alkylation of $\mathrm{sp}^{2}$ and $\mathrm{sp}^{3}$ Carbon-Hydrogen Bonds. J. Am. Chem. Soc. 2010, 132, 3965-3972. (d) Zatolochnaya, O.V.; Gevorgyan, V. The Road Less Travelled to Amination. Nat. Chem. 2014, 6, 661-663. (e) Timsina, Y.N.; Gupton, B.F.; Ellis, K.C. Palladium-Catalyzed C-H Amination of C( $\left.\mathrm{sp}^{2}\right)$ and C( $\left.\mathrm{sp}^{3}\right)$ H Bonds: Mechanism and Scope for N-Based Molecule Synthesis. ACS Catal. 2018, 8, 5732-5776. (f) Dhakshinamoorthy, A.; Asiri, A.; Garcia, H. Formation of C-C and C-Heteroatom Bonds by C-H Activation by Metal Organic Frameworks as Catalysts or Supports. ACS Catal. 2019, 9, 1081-1102. (g) Zhou, Z.; Kürti, L. Electrophlic Amination: An Update. Synlett. 2019, 30, 1525-1535.

${ }^{4}$ (a) Hazelard, D.; Nocquet, P.; Compain, P. Catalytic C-H Amination at its Limits: Challenges and Solutions. Org. Chem. Front. 2017, 4, 2500-2521. (b) Collet, F.; Dodd, R.H.; Dauban, P. Catalytic C-H Amination: Recent Progress and Future Directions. Chem. Commun., 2009, 34, 5061-5074. (c) Ramirez, T.A.; Zhao, B.; Shi, Y. Recent Advances in Transition Metal-Catalyzed sp ${ }^{3} \mathrm{C}-\mathrm{H}$ Amination Adjacent to Double Bonds and Carbonyl Groups. Chem. Soc. Rev. 2012, 41, 921-942. (d) Gutekunst, W.R.; Baran, P.S. C-H Functionalization Logic in Total Synthesis. Chem. Soc. Rev., 2011, 40, 1976-1991. (e) Jeffrey, J. L.; Sarpong, R. Intramolecular C(sp $\left.{ }^{3}\right)$-H Amination. Chem. Sci., 2013, 4, 4092-4106.

${ }^{5}$ (a) Arai, A.; Ueda, Y.; Morisaki, K.; Furuta, T.; Sasamori, T.; Tokitoh, N.; Kawabata T. Intermolecular Chemo- and regioselective Aromatic C-H Amination of Alkoxyarenes Promoted by Rhodium Nitrenoids. Chem. Commun., 2018, 54, 2264-2267. (b) Kono, M.; Harada, S.; Nemoto, T. Rhodium-Catalyzed Stereospecific C-H Amination for the 
Construction of Spiroaminal Cores: Reactivity Difference between Nitrenoid and Carbenoid Species against Amide Functionality. Chem. Eur. J. 2017, 23, 7428-7432. (c) Rauser, M.; Ascheberg, C.; Niggemann, M. Angew. Chem. Int. Ed. 2017, 56, 11570-11574. (d) Starkov, P.; Jamison, T.F.; Marek, I. Electrophilic Amination: The Case of Nitrenoids. Chem. Eur. J. 2015, 21, 5278 - 5300. (e) Ramierez, T.A.; Zhao, B.; Shi, Y. Recent Advances in Transition MetalCatalyzed sp ${ }^{3}$ C-H Amination Adjacent to Double Bonds and Carbonyl Groups. Chem. Soc. Rev. 2012, 41, 931-942. (f) Collet, F.; Lescot, C.; Dauban, P. Catalytic C-H Amination: The Stereoselectivity Issue. Chem. Soc. Rev. 2011, 40, 1926-1936. (g) Bois, J.D. Rhodium-Catalyzed C-H Amination. An Enabling Method for Chemical Synthesis. Org. Process Res. Dev. 2011, 15, 758-762. (h) Aguila, J. B.; Badiei, Y. M.; Warren, T. H. Mechanistic Insights into C-H Amination via Dicopper Nitrenes. J. Am. Chem. Soc. 2013, 135, 9399- 9406. (i) Zhang, X.; Xu, H.; Liu, X.; Phillips, D.L.; Zhao, C. Mechanistic Insight into the Intramolecular Benzylic C-H Nitrene Insertion Catalyzed by Bimetallic Paddlewheel Complexes: Influence of the Metal Centers. Chem. Eur. J., 2016, 22, 7288 - 7297.

${ }^{6}$ (a) Hu, X.; Qi, X.; Chen, J.; Zhao, Q.; Wei, Q.; Lan, Y.; Xia, W. Catalytic N-Radical Cascade Reaction of Hydrazones by Oxidative Deprotonation Electron Transfer and TEMPO Mediation. Nat. Commun. 2016, 7, 11188-

11200. (b) Nicolaou, K.C.; Baran, P.S.; Zhong, Y.-L.; Barluenga, S.; Hunt, K.W.; Kranich, R.; Vega, J.A. Iodine (V) Reagents in Organic Synthesis. Part 3. New Routes to Heterocyclic Compounds via o-Iodoxybenzoic Acid-Mediated Cyclizations: Generality, Scope, and Mechanism. J. Am. Chem. Soc. 2002, 124, 2233-2244. (c) Wang, Y.; Chen, H.; Zhu, X.; Chiba, S. Copper-Catalyzed Aerobic Aliphatic C-H Oxygenation Directed by an Amidine Moiety. J. Am. Chem. Soc. 2012, 134, 11980-11983. (d) Cecere, G.; König, C.M.; Alleva, J.L.; MacMillan, D.W.C.

Enantioselective Direct $\alpha$-Amination of Aldehydes via a Photoredox Mechanism: A Strategy for Asymmetric Amine Fragment Coupling. J. Am. Chem. Soc. 2013, 135, 11521-11524. (e) Allen, L. J.; Cabrera, P. J.; Lee, M.; Sanford, M. S. N-Acyloxyphthalimides as Nitrogen Radical Precursors in the Visible Light Photocatalyzed Room Temperature C-H Amination of Arenes and Heteroarenes. J. Am. Chem. Soc. 2014, 136, 5607-5610. (f) Tranatino, K.T.; Miller, D.C.; Callon, T.A.; Knowles, R.R. Bond-Weakening Catalysis: Conjugate Aminations Enabled by the Soft Homolysis of Strong N-H Bonds. J. Am. Chem. Soc. 2015, 137, 6440-6443.

${ }^{7}$ (a) Hofmann, A. W. Zur Kenntniss des Piperidins und Pyridins. Ber. Dtsch. Chem. Ges. 1879, 12, 984-990. (b)Wolff, M. Cyclization of N-Halogenated Amines (The Hofmann-Löffler Reaction). Chem. Rev. 1963, 63, 55-64. 8 (a) McManus, J.B.; Onuska, N.P.R.; Nicewicz, D.A. Generation and Alkylation of $\alpha$-Carbamyl Radicals via Organic Photoredox Catalysis. J. Am. Chem. Soc. 2018, 140, 9056-9060. (b) Margrey, K. A.; Leven, A.; Nicewicz, D.A. Direct Aryl C-H Amination with Primary Amines Using Organic Photoredox Catalysis. Angew. Chem. Int. Ed. 2017, 56, 15644-15648. (c) Shaw, M.H.; Shurtleff, V. W.; Terrett, J. A.; Cuthbertson, J.D.; MacMillan, D.W.C. Native Functionality in Triple Catalytic Cross-Coupling: $\mathrm{sp}^{3} \mathrm{C}-\mathrm{H}$ bonds as Latent Nucleophiles. Sciene. 2016, 352, 1304-1308. (d) Jeffrey, J.L.; Petronijević, F.R.; MacMillan, D.W.C. Selective Radical-Radical Cross-Couplings: Design of a Formal $\beta$-Mannich Reaction. J. Am. Chem. Soc. 2015, 137, 8404-8407. (e) Prier, C.K.; MacMillan, D.W.C. Amine $\alpha$-Heteroarylation via Photoredox Catalysis: A Homolytic Aromatic Substitution Pathway. Chem. Sci., 2014, 5, 4173-4178. (f) Bartling, H.; Eisenhofer, A.; König, Gschwind, R.M. The Photocatalyzed Aza-Henry Reaction of $\mathrm{N}$-Aryltetrahydroisoquinolines: Comprehensive Mechanism, $\mathrm{H}$ Radical versus $\mathrm{H}^{+}$-Abstraction, and Background Reactions. J. Am. Chem. Soc., 2016, 138, 11860-11871.

${ }^{9}$ Evoniuk, C. J.; Hill, S. P.; Hanson, K.; Alabugin, I. V. Double C-H Amination by Consecutive SET Oxidations. Chem. Commun., 2016, 52,7138-7141.

${ }^{10}$ Evoniuk, C. J.; Gomes, G. P.; Hill, S.; Satoshi, F.; Hanson, K.; Alabugin, I. V. Coupling N-H Deprotonation, C-H Activation, and Oxidation: Metal-Free $\mathrm{C}\left(\mathrm{sp}^{3}\right)-\mathrm{H}$ Aminations with Unprotected Anilines. J. Am. Chem. Soc., 2017, 139, 16210-16221.

${ }^{11}$ (a) Yang, M.; Su, B.; Wang, Y.; Chen, K.; Jiang, X.; Zhang, Y.; Zhang, X.; Chen, G.; Cheng, Y.; Cao, Z.; Guo, Q.; Wang, L.; Shi, Z. Silver-Catalysed Direct Amination of Unactivated C-H Bonds of Functionalized Molecules. Nat. Comm. 2014, 5, 4707-4713. (b) Timsina, Y.; Gupton, F.; Ellis, K. Palladium-Catalyzed C-H Amination of $\mathrm{C}\left(\mathrm{sp}^{2}\right)$ and $\mathrm{C}\left(\mathrm{sp}^{3}\right)-\mathrm{H}$ Bonds: Mechanism and Scope for N-Based Molecule Synthesis. ACS Catal. 2018, 8, 57325776. (c) Wang, Z.; Ni, J.; Kuninobu, Y.; Kanai, M. Copper-Catalyzed Intramolecular C( $\left(\mathrm{sp}^{3}\right)-\mathrm{H}$ and C(sp²)-H Amidation by Oxidative Cyclization. Angew. Chem. Int. Ed. 2014, 53, 3496 -3499. (d) He, G.; Zhang, S.; Nack, W.; Li, Q.; Chen, G. Use of a Readily Removable Auxiliary Group for the Synthesis of Pyrrolidones by the PalladiumCatalyzed Intramolecular Amination of Unactivated $\gamma \mathrm{C}\left(\mathrm{sp}^{3}\right)$-H Bonds. Angew. Chem. Int. Ed. 2013, 52, $11124-$ 11128. (e) Wu, X.; Zhao, Y.; Ge, H. Nickel-Catalyzed Site-Selective Amidation of Unactivated C( $\left(\mathrm{sp}^{3}\right)$-H Bonds. Chem. Eur. J. 2014, 20, 9530 - 9533. (f) Neumann, J. J.; Rakshi, S.; Dröge, T.; Glorius, F. Palladium-Catalyzed Amidation of Unactivated C( $\left(\mathrm{sp}^{3}\right)$-H Bonds: From Anilines to Indolines. Angew. Chem. Int. Ed. 2009, 48, 68926895.

${ }^{12}$ Labinger, J. A.; Bercaw, J. E. Understanding and Exploiting C-H Bond Activation. Nature. 2002, 417, 507-514. 
${ }^{13}$ (a) Tan, Y.; Hartwig, J. F. Palladium-Catalyzed Amination of Aromatic C-H Bonds with Oxime Esters. J. Am. Chem. Soc. 2010, 132, 3676-3677. (b) Youn, S. W.; Bihn, J. H.; Kim, B. S. Pd-Catalyzed Intramolecular Oxidative C-H Amination: Synthesis of Carbazoles. Org. Lett. 2011, 13, 3738-3741. (c) Hartwig, J. F. Electronic Effects on Reductive Elimination to Form Carbon-Carbon and Carbon-Heteroatom Bonds from Palladium (II) Complexes. Inorg. Chem. 2007, 46, 1936-1947. (d) Jordan-Hore, J. A.; Johansson, C. C. C.; Gulias, M.; Beck, E. M.; Gaunt, M. J. Oxidative Pd(II)-Catalyzed C-H Bond Amination to Carbazole at Ambient Temperature. J. Am. Chem. Soc. 2008, 130, 16184-16186.

${ }^{14}$ Studer, A. The Persistent Radical Effect in Organic Synthesis. Chem. Eur. J. 2001, 7, 1159-1164.

${ }^{15}$ (a) West, S.P.; Bisai, A.; Lim, A.D.; Narayan, R.R.; Sarpong, R. Total Synthesis of (+)-Lyconadin A and Related Compounds via Oxidative C-N Bond Formation. J. Am. Chem. Soc. 2009, 131, 11187-11194 (b) Gruver, J.M.; West, S.P.; Collum, D.B.; Sarpong, R. Experimental Characterization and Computational Study of Unique C,NChelated Lithium Dianions. J. Am. Chem. Soc. 2010, 132, 13212-13213. (c) Jeffrey, J.L.; Bartlett, E.B.; Sarpong, R. Intramolecular $\mathrm{C}\left(\mathrm{sp}^{3}\right)-\mathrm{N}$ Coupling by Oxidation of Benzylic C,N-Dianions. Angew. Chem. Int. Ed. 2013, 52, 21942197.

${ }^{16}$ Syroeshkin, M. A.; Kuriakose, F.; Saverina, E. A.; Timofeeva, V. A.; Egorov, M. P.; Alabugin, I. V. Upconversion of Reductants. Angew. Chem. Int. Ed. 2019, 58, 5532-5550.

${ }^{17}$ For the general review of dehydrogenative $\mathrm{C}-\mathrm{O}$ bond formation, see: Krylov, I. B.; Vil', V A. Terent'ev, A. O. Cross-dehydrogenative Coupling for the Intermolecular C-O Bond Formation. Beilstein J. Org. Chem. 2015, 11, 92 146.

${ }^{18}$ (a) Hardcastle, I. R.; Ahmed, S. U.; Atkins, H.; Farnie, G.; Golding, B. T.; Griffin, R. J.; Guyenne, S.; Hutton, C.; Källblad, P.; Kemp, S. J.; Kitching, M. S.; Newell, D. R.; Norbedo, S.; Northen, J.; Reid, R. J.; Saravanan, K.; Willems, H. M.; Lunec, J. Small-Molecule Inhibitors of the MDM2-p53 Protein-Protein Interaction Based on an Isoindolinone Scaffold. J. Med. Chem. 2006, 49, 6209-6221. (b) Riedinger, C.; Endicott, J.A.; Kemp, S.J.; Smyth, L.A.; Watson, A.; Valeur, E.; Golding, B.T.; Griffin, R.J.; Hardcastle, I.R.; Noble, M.E. ; McDonnell J.M. Analysis of Chemical Shift Changes reveals the Binding Modes of Isoindolinone Inhibitors of the MDM2-p53 Interaction. $J$. Am. Chem. Soc. 2008, 130, 16038-16044. (c) Hardcastle, I. R.; Liu, J.; Valeur, E.; Watson, A.; Ahmed, S. U.; Blackburn, T. J.; Bennaceur, K.; Clegg, W.; Drummond, C.; Endicott, J. A.; Golding, B. T.; Griffin, R. J.; Gruber, J.; Haggerty, K.; Harrington, R. W.; Hutton, C.; Kemp, S.; Lu, X.; McDonnell, J. M.; Newell, D. R.; Noble, M. E.; Payne, S. L.; Revill, C. H.; Riedinger, C.; Xu, Q.; Lunec, J. Isoindolinone Inhibitors of the Murine Double Minute 2 (MDM2)-p53 Protein-Protein Interaction: Structure-Activity Studies Leading to Improved Potency. J. Med. Chem.

2011, 54, 1233-1243. (d) Watson, A.F.; Liu, J.; Bennaceur, K.; Drummond, C.J.; Endicott, J.A.; Golding, B.T.; Griffin, R.J.; Haggerty, K.; Lu, X.; McDonnell, J.M.; Newell, D.R.; Noble, M.E.M.; Revill, C.H.; Riedinger, C.; Xu, Q.; Zhao, Y.; Lunec, J.; Hardcastle, I.R. MDM2-p53 Protein-Protein Interaction Inhibitors: A-ring Substituted Isoindolinones. Bioorg. Med. Chem. Lett. 2011, 21, 5916-5919. (e) Grigoreva, T.A.; Novikova, D.S.; Petukhov, A.V.; Gureev, M.A.; Garabadzhiu, A.V.; Melino, G.; Barlevv, N.A.; Tribulovich, V.G. Proapoptotic Modification of Substituted Isoindolinones as MDM2-p53 Inhibitors. Bioorg. Med. Chem. Lett. 2017, 27, 5197-5202.

${ }^{19}$ Topliss, J.G.; Konzelman, L.M.; Sperber, N.; Franklin, E.R. Antihypertensive Agents. III. 3-Hydroxy-3phenylphthalimidines. J. Med. Chem. 1964, 7, 453-456.

${ }^{20}$ (a) Fajardo, V.; Elango, V.; Cassels, B. K.; Shamma, M. Chilenine: An Isoindolobenzazepine Alkaloid. Tetrahedron Lett. 1982, 23, 39-42. (b) Kamauchi, H.; Shiraishi, Y.; Kojima, A.; Kawazoe, N.; Kinoshita, L.; Koyama, K. Isoindolinoes, Phthalides, and a Naphthoquinone from the Fruiting Body of Daldinia concerntrica. J. Nat. Prod. 2018, 81, 1290-1294.

${ }^{21}$ Chen, M.-W.; Chen, Q.-A.; Duan, Y.; Ye, Z.-S.; Zhou, Y.-G. Asymmetric Hydrogenolysis of Racemic tertiary Alcohols, 3-substituted 3-hydroxyisoindolin-1-ones. Chem. Comm. 2012, 48, 1698-1700.

${ }^{22}$ Kang, Z.; Zhang, D.; Shou, J.; Hu, W. Enantioselective Trapping of Oxonium Ylides by 3-Hydroxyisoindolinones via a Formal $S_{\mathrm{N}} 1$ Pathway for Construction of Contiguous Quaternary Stereocenters. Org. Lett. 2018, 20, 983-986.

${ }_{23}$ (a) Nishimura, T.; Nagamoto, M.; Ebe, Y.; Hayashi, T. Enantioselective [3+2] Annulation via C-H Activation between cyclic $N$-acyl Ketimines and 1,3-dienes Catalyzed by Iridium/Chiral Diene Complexes. Chem. Sci. 2013, 4, 4499-4504, (b) Sharma, S.; Oh, Y.; Mishra, N.K.; De, U.; Jo, H.; Sachan, R.; Kim, H.S.; Jung, Y.H.; Kim, I.S. Rhodium-Catalyzed [3+2] Annulation of Cyclic $N$-Acyl Ketimines with Activated Olefins: Anticancer Activity of Spiroisoindolinones. J. Org. Chem. 2017, 82, 3359-3367. (c) Nagamoto, M.; Nishimura, T. Catalytic [3+2] Annulation of Ketimines with Alkynes via C-H Activation by Cationic Iridium(cod) Complex. Chem. Comm. 2014, 50, 6274 - 6277. (d) Nishimura, T.; Noishiki, A.; Ebe, Y.; Hayashi, T. Hydroxorhodium/Chiral Diene Complexes as Effective Catalysts for the Asymmetric Arylation of 3-Aryl-3-hydroxyisoindolin-1-ones. Angew. Chem. Int. Ed. 2013, 52, 1777-1780. 
${ }^{24}$ U. S. Department of Health and Human Services Food and Drug Administration (2015). Q3D Elemental Impurities Guidance for Industry.

25 (a) Wasserman, H. H.; Ives, J. 1. Singlet Oxygen in Organic Synthesis. Tetrahedron, 1981, 37, 1825-1852. (b) Ogilby, P. R. Singlet Oxygen: There is Indeed Something New Under the Sun. Chem. Soc. Rev. 2010, 39, 31813209. (c) Ghogare, A. A.; Greer, A. Using Singlet Oxygen to Synthesize Natural Products and Drugs. Chem. Rev. 2016, 116, 9994-10034.

${ }^{26}$ (a) Gao , Y.; Hu, G.; Zhong, J.; Shi, Z.; Zhu, Y.; Su, D.; Wang, J. Nitrogen-Doped sp²-Hybridized Carbon as a Superior Catalyst for Selective Oxidation. Angew. Chem. Int. Ed. 2013, 52, 2109-2113. (b) Urgoita, G.; SanMartin, R.; Herrero, M.T.; Domínguez, E. An Outstanding Catalyst for the Oxygen-Mediated Oxidation of Arylcarbinols, Arylmethylene and Arylacetylene Compounds. Chem. Commun., 2015, 51, 4799-4802. (c) Ma, J.; Hu, Z.; Li, M.; Zhao, W.; Hu, X.; Mo, W.; Hu, B.; Sun, N.; Shen, Z. DDQ/tert-Butyl nitrite-catalyzed aerobic oxidation of diarylmethane $\mathrm{sp}^{3} \mathrm{C}-\mathrm{H}$ Bonds. Tetrahedron, 2015, 71, 6733-6739. (d) Wang, H.; Wang, Z.; Huang, H.; Tan, J.; Xu, K. KO'Bu-Promoted Oxidation of (Hetero)benzylic $\mathrm{Csp}^{3}$-H to Ketones with Molecular Oxygen. Org. Lett., 2016, 18, 5680-5683. (e) Guo, C.; Zhang, Y.; Zhang, Y.; Wang, J. An Efficient Approach for Enhancing the Catalytic Activity of Ni-MOF-74 via a Relay Catalyst System for the Selective Oxidation of Benzylic C-H Bonds Under Mild Conditions. Chem. Commun. 2018, 54, 3701-3704. (f) Sterckx, H.; Morel, B.; Maes, B.U.W. Catalytic Aerobic Oxidation of $\mathrm{C}\left(\mathrm{sp}^{3}\right)$-H Bonds. Angew. Chem. Int. Ed. 2019, 58, 7946-7970.

${ }^{27}$ The M06-2X functional has demonstrated good thermodynamic data for organic reactions. For more details, see: (a) Zhao, Y.; Truhlar, D. G. The Mo6 Suite of Density Functionals for Main Group Thermochemistry, Thermochemical Kinetics, Noncovalent Interactions, Excited States, and Transition Elements: Two New Functionals and Systematric Testing of Four Mo6-class Functionals and 12 ofther Functions. Theor. Chem. Acc., 2008, 120, 215-241. (b) Zhao, Y.; Truhlar, D. G. Density Functionals with Broad Applications in Chemistry. Acc. Chem. Res., 2008, 41, 157-167.

${ }^{28}$ Marenich, A. V.; Cramer, C. J.; Truhlar, D. G. Universal Solvation Model Based on Solute Electron Density and on a Continuum Model of the Solvent Defined by the Bulk Dielectric Constant and Atomic Surface Tensions. J. Phys. Chem. B 2009, 113, 6378-6378.

${ }^{29}$ Grimme, S.; Antony, J.; Ehrlich, S.; Krieg, H. A Consistent and Accurate ab initio Parametrization of Density Functional Dispersion Correction (DFT-D) for the 94 Elements H-Pu. J. Chem. Phys., 2010, 132, 154104.

${ }^{30}$ Frisch, M. J.; Trucks, G. W.; Schlegel, H. B.; Scuseria, G. E.; Robb, M. A.; Cheeseman, J. R.; Scalmani, G.; Barone, V.; Mennucci, B.; Petersson, G. A.; Nakatsuji, H.; Caricato, M.; Li, X.; Hratchian, H. P.; Izmaylov, A. F.; Bloino, J.; Zheng, G.; Sonnenberg, J. L.; Hada, M.; Ehara, M.; Toyota, K.; Fukuda, R.; Hasegawa, J.; Ishida, M.; Nakajima, T.; Honda, Y.; Kitao, O.; Nakai, H.; Vreven, T.; Montgomery, J. A., Jr.; Peralta, J. E.; Ogliaro, F.; Bearpark, M.; Heyd, J. J.; Brothers, E.; Kudin, K. N.; Staroverov, V. N.; Kobayashi, R.; Normand, J.; Raghavachari, K.; Rendell, A.; Burant, J. C.; Iyengar, S. S.; Tomasi, J.; Cossi, M.; Rega, N.; Millam, M. J.; Klene, M.; Knox, J. E.; Cross, J. B.; Bakken, V.; Adamo, C.; Jaramillo, J.; Gomperts, R.; Stratmann, R. E.; Yazyev, O.; Austin, A. J.; Cammi, R.; Pomelli, C.; Ochterski, J. W.; Martin, R. L.; Morokuma, K.; Zakrzewski, V. G.; Voth, G. A.; Salvador, P.; Dannenberg, J. J.; Dapprich, S.; Daniels, A. D.; Farkas, Foresman, J. B.; Ortiz, J. V.; Cioslowski, J.; Fox, D. J. Gaussian, Inc., Wallingford CT, 2009.

${ }^{31}$ CYLview, 1.0b; Legault, C. Y., Université de Sherbrooke, 2009 (http://www.cylview.org)

${ }^{32}$ ChemCraft 1.8 http://www.chemcraftprog.com, accessed in February 2016.

${ }^{33}$ For the effect of such geometric changes on stability and reactivity, see: Komarov, I. V.; Yanik, S.; Ishchenko, A. Y.; Davies, J. E.; Goodman, J. M.; Kirby, A. J. The Most Reactive Amide As a Transition-State Mimic For cistrans InterconversionJ. Am. Chem. Soc. 2015, 137, 926-930. Hutchby, M.; Houlden, C. E.; Haddow, M. F.; Tyler, S. N. G.; Lloyd-Jones, G. C.; Booker-Milburn, K. I. Switching Pathways: Room-Temperature Neutral Solvolysis and Substitution of Amides. Angew. Chem. 2012, 124, 563-566. Szostak, M.; Aube, J. Chemistry of Bridged Lactams and Related Heterocycles. Chem. Rev. 2013, 113, 5701-5765. Vatsadze, S. Z.; Loginova, Y. D.; Gomes, G.; Alabugin, I. V. Stereoelectronic Chameleons: The Donor-Acceptor Dichotomy of Functional Groups. Chem. Eur. J., 2017, 23, 3225-3245.

${ }^{34}$ Peterson, P.; Shevchenko, N.; Breiner, B.; Manoharan, M.; Lufti, F.; Delaune, J.; Kingsley, M.; Kovnir, K.; Alabugin, I. V. Orbital Crossings Activated through Electron Injection: Opening Communication between Orthogonal Orbitals in Anionic C1-C5 Cyclizations of Enediynes. J. Am. Chem. Soc., 2016, 138, 15617-15628.

${ }_{35}$ Cotton, F.A.; Wilkinson, G.; Murillo, C.A.; Bochmann, M. Advanced Inorganic Chemistry (6th ed.); Wiley: New York, 1999, p. 461.

${ }^{36}$ Burton, G.W.; Ingold, K.U. Autoxidation of Biological Molecules. 1. Antioxidant Activity of Vitamine E and Related Chain-Breaking Phenolic Antioxidants in vitro. J. Am. Chem. Soc. 1981, 103, 6472-6477. 
${ }^{37}$ (a) Bothe, E.; Schuchmann, M. N.; Schulte-Frohlinde, D.; Sonntag, C. Z. Hydroxyl Radical-Induced Oxiation of Ethanol in Oxygenated Aqueous Solutions. A Pulse Radiolysis and Product Study. Naturforsch. B: J. Chem. Sci. 1983, 38, 212-219. (b) Song, W.; Xu, T.; Cooper, W. J.; Dionysiou, D. D.; Cruz, A. A. de la; O’Shea, K. E. Radiolysis Studies on the Destruction of Microcystin-LR in Aqueous Solution by Hydroxyl Radicals. Environ. Sci. Technol. 2009, 43, 1487-1492. (c) Dorfman, L. M.; Adams, G. E. Reactivity of the Hydroxyl Radical in Aqueous Solutions; U.S. National Bureau of Standards: Washington, DC, 1973. Chen, H.; Lin, L.; Lin, Z.; Guo, G.; Lin, J. M. J. Phys. Chem. A 2010, 114, 10049-10058.

38 (a) Nanni, E. J.; Sawyer, D. T.; Ball, S. S.; Bruice, T. C. Chemistry of Higher Order, Mixed Oranocuprates. 1. Substituion Reaction at Unactivated Secondary Centers. J. Am. Chem. Soc. 1981, 103, 2797-2802. (b) Sawyer, D. T.; Nanni, E.J.; Roberts, Jr., J. L. Electrochemical and Spectrochemicla Studies of Biological Redox Components. 1982, 585-600. (c) Hayyan, M.; Hasim, M. A.; AlNashef, I. M. Superoxide Ion: Generation and Chemical Implications. Chem. Rev. 2016, 116, 3029-3085.

${ }^{39}$ (a) Nanni Jr., E. J.; Stallings, M. D.; Sawyer, D. T. Does Superoxide Ion Oxidize Catechol, $\alpha$-Tocopherol, and Ascorbic acid by Direct Electron Transfer? J. Am. Chem. Soc., 1980, 102, 4481- 4485. (b) Chin, D-H.; Chiericato Jr., G.; Nanni Jr, E. J.; Sawyer, D. T. Proton-Induced Disproportionation of Superoxide ion in Aprotic Media. J. Am. Chem. Soc., 1982, 104, 1296-1299.

${ }^{40}$ Note that the peroxide moiety in this molecule would engage in the anomeric $\mathrm{nO} \rightarrow \sigma^{*} \mathrm{C}-\mathrm{N}$ interaction. Such interactions were shown to significantly stabilize peroxides with geminal acceptor groups: Stereoelectronic source of the anomalous stability of bis-peroxides. (a) Gomes, G. P.; Vil', V.; Terent'ev, A.; Alabugin, I. V. Stereoelectronic Source of the Anomalous Stability of Bis-peroxides. Chem. Sci., 2015, 6, 6783 - 6791. (b) Vil', V. A.; Gomes, G. P.; Bityukov, O. V.; Lyssenko, K. A.; Nikishin, G. I.; Alabugin, I. V.; Terent'ev, A. O. Interrupted Baeyer-Villiger Rearrangement: Building A Stereoelectronic trap for the Criegge Intermediate. Angew. Chem. Int. Ed., 2018, 57, 3372-3376. (c) Juaristi, E.; Gomes, G. P.; Terent'ev, A. O.; Notario, R.; Alabugin, I. V. Stereoelectronic Interactions as a Probe for the Existence of the Intramolecular $\alpha$-Effect. J. Am. Chem. Soc., 2017, 139, 10799-10813. (d) Gomes, G. P.; Yaremenko, I. A.; Radulov, P. S.; Novikov, R. A.; Chernyshev, V. V.; Korlyukov, A. A.; Nikishin, G. I.; Alabugin, I. V.; Terent'ev, A. O. Stereoelectronic Control in the Ozone-Free Synthesis of Ozonides. Angew. Chem. Int. Ed., 2017, 56, 4955-4959.

${ }^{41}$ Swern, D.; Clements, A. H.; Lung, T. M. Nuclear Magnetic Resonance Spectra of Organic Peroxides. Anal. Chem. 1969, 41, 412-416.

42 (a) Schultz, D.M.; Levesque, F.; DiRocco, D.A.; Reibarkh, M.; Ji, Y.; Joyce, L.A.; Dropinski, J.F.; Sheng, H.; Sherry, B.D.; Davies, I.W. Oxyfunctionalization of the Remote C-H Bonds of Aliphatic Amines by Decatungstate Photocatalysis. Angew. Chem. Int. Ed., 2017, 56, 15274-15278. (b) Tsang, A.S.-K.; Kapat, A.; Schoenebeck, F. Factors that Control C-C Cleavage versus C-H Bond Hydroxylation in Copper-Catalyzed Oxiations of Ketones with $\mathrm{O}_{2}$ J. Am. Chem. Soc., 2016, 138, 518-526. (c) Liu, K.-J.; Duan, Z.-H.; Zeng, X.-L.; Sun, M.; Tang, Z.; Jiang, S.; Cao, Z.; He, W.-M. Fast, Base-Free and Aqueous Synthesis of Quinolin-2 (1H)-ones Under Ambient Conditions. ACS Sustainable Chem. Eng., 2019, 7, 10293-10298. (d) Lesieur, M.; Genicot, C.; Pasau, P. Development of a Flow Photochemical Aerobic Oxidation of Benzylic C-H Bonds. Org. Lett., 2018, 20, 1987-1990.

${ }^{43}$ (a) Griesser, M.; Shah, R.; Van Kessel, A. T.; Zilka, O.; Haidasz, E. A.; Pratt, D. A. The Catalytic Reaction of Nitroxides with Peroxyl Radicals and Its Relevance to their Cytoprotective Properties. J. Am. Chem. Soc. 2018, 140, 3798-3808. (b) Samuni, A.; Krishna, C. M.; Riesz, P.; Finkelstein, E.; Russo, A. A Novel Metal-Free Low Molecular Weight Superoxide Dismutase Mimic. J. Biol. Chem. 1988, 263, 17921-17924. (c) Mitchell, J. B.; Samuni, A.; Krishna, M. C.; DeGraff, W. G.; Ahn,M. S.; Samuni, U.; Russo, A. Biologically Active MetalIndependent Superoxide Dismutase Mimics. Biochemistry. 1990, 29, 2802-2807. (d) Krishna, M. C.; Grahame, D. A.; Samuni, A.; Mitchell, J. B.;Russo, A.Proc. Oxoammonium Cation Intermediate in the Nitroxide Catalyzed Dismutation of Superoxide. Natl. Acad. Sci. U. S. A. 1992, 89, 5537-5541.(e) Krishna, M. C.; Russo, A.; Mitchell, J. B.; Goldstein, S.; Dafni,H.; Samuni, A. Do Nitroxide Antioxidants Act as Scavengers of $\mathrm{O}_{2}{ }^{--}$or as SOD Mimics. J. Biol. Chem. 1996, 271, 26026-26031.

44 (a) Bobbit, J. M.; Brückner, C.; Merbouh, N. Oxoammonium- and Nitroxide-Catalyzed Oxidations of Alcohols. Org. React. 2009, 74, 103. (b) Richter, H.; Mancheño, O. G. Dehydrogenative Functionalization of C( $\left.\mathrm{sp}^{3}\right)-\mathrm{H}$ Bonds Adjacent to a Heteroatom Mediated by Oxoammonium Salts. Eur. J. Org. Chem. 2010, 2010, 4460-4467. (c) Neel, A. J.; Hehn, J. P.; Tripet, P. F.; Toste, F. D. Asymmetric Cross-Dehydrogenative Coupling Enabled by the Design and Application of Chiral triazole-Containing Phosphoric Acids. J. Am. Chem. Soc. 2013, 135, 14044-14047. (d) Tarantino, K. T.; Miller, D.C.; Callon, T. A.; Knowles, R. R. Bond-Weakening Catalysis: Conjugate Aminations Enabled by the Soft Homolysis of Strong N-H Bonds. J. Am. Chem. Soc. 2015, 137, 6440- 6443.

${ }^{45}$ Zhang, Z.; Gao, Y.; Liu, Y.; Li, J.; Xie, H.; Li, H.; Wang, W. Organocatalytic Aerobic Oxidation of Benzylic sp ${ }^{3}$ C-H Bonds of Ethers and Alkylarenes Promoted by a Recyclable TEMPO Catalyst. Org. Lett. 2015, 17, 5492-5495. 
${ }^{46}$ (a) Semmelhack, M. F.; Schmid, C. R.; Cortes, D. A. Mechanism of the Oxidation of Alcohols by 2,2,6,6Tetramethylpiperidine Nitrosonium Cation. Tetrahedron Lett. 1986, 27, 1119-1122. (b) Hamlin, T.A.; Kelly, C.B.; Ovian, J.M.; Wiles, R.J.; Tilley, L.J.; Leadbeater, N.E. Toward a Unified Mechanism for Oxoammonium SaltMediated Oxidation Reactions: A Theoretical and Experimental Study Using a Hydride Transfer Model. J. Org. Chem. 2015, 80, 8150-8167. (c) Richter, H.; Mancheño, O.G. Dehydrogenative Functionalization of C( $\mathrm{sp}^{3}$ )-H Bonds Adjacent to a Heteroatom Mediated by Oxoammonium Salts. Eur. J.Org. Chem. 2010, 4460-4467. (d) Dong, J.; Xia, Q.; Yan, C.; Song, H.; Liu, Y.; Wang, Q. C( $\left(\mathrm{sp}^{3}\right)$-H Azidation Reaction: A protocol for Preparation of Aminals. J. Org. Chem. 2018, 83, 4516-4524. 